\title{
Numerical and experimental study of laboratory and full-scale prototypes of the novel solar multi-surface air collector with double-receiver tubes integrated into a greenhouse heating system
}

Chao Chen ${ }^{1 *}$, Fengtao Han ${ }^{1}$, Khamid Mahkamov ${ }^{2}$, Shen $\mathrm{Wei}^{3}$, Xinglong Ma ${ }^{4}$, Haoshu Ling $^{5}$, Chen Zhao ${ }^{1}$

1. College of Architecture and Civil Engineering, Beijing University of Technology, Beijing 100124, P R China

2. Faculty of Engineering and Environment, Northumbria University, Newcastle upon Tyne, UK

3. The Bartlett School of Construction and Project Management, University College London (UCL), 1-19 Torrington Place, London WC1E 7HB, United Kingdom.

4. School of Mechanical Engineering, Beijing Institute of Technology, Beijing 100081, China

5. Institute of Engineering Thermophysics, Chinese Academy of Sciences, Beijing 100190, P R China

\section{Highlights :}

- The laboratory and full-scale prototypes of the novel solar air collector were tested;

- Fuel economy achieved in tests varies from $11 \%$ to $81 \%$ depending on weather conditions;

- The increased concentration ratio of about 1.4 was obtained without a sun-tracking device;

- The mathematical model of the collector was validated against experimental results;

- The model was used to define the rational design parameters of the full-scale prototype.

\begin{abstract}
The application of greenhouse technologies is rapidly expanding in China and other regions of the world with the continental climate. Such technologies are characterized by a considerable consumption of fossil fuels, especially in winter periods. Various renewable energy technologies are used to reduce the energy demand in greenhouses, including solar heating. Simpler designs of water or air solar collectors are preferred without sun-tracking devices and reduced dimensions and weight. In this work, a novel solar multi-surface air collector with double-receiver tubes,


which does not require a sun-tracking device is proposed and has increased concertation ratio and sun rays convergence and reduced thermal losses. The laboratory and full-scale prototypes of the proposed novel collector were manufactured and tested in laboratory conditions during the December-January period as a part of the greenhouse with the active-passive ventilation wall and latent thermal storage, located in the Beijing Region. Results of experiments demonstrate that the solar collector increases the average temperatures of the greenhouse north wall inner surface by $7.5^{\circ} \mathrm{C}$, indoor air during the night-time by $1.8{ }^{\circ} \mathrm{C}$ and indoor soil by $1.5^{\circ} \mathrm{C}$. The novel collector provided active heat gains of 11.831 GJ during the December-January period and satisfied from $11 \%$ to $81 \%$ of the heat load. A lumped parameter mathematical model of the proposed collector was developed, and the comparison of simulation results and experimental data demonstrate its high accuracy in prediction of the collector performance. The model was used to study the influences of outdoor meteorological parameters, air velocity in the receiver tubes and their length on the performance of the collector. This data was used to determine the rational design parameters and air velocity of the full-scale collector. The model was also used to rationalize the variation of air velocity in the receiver tube during the day.

Keywords: solar air collector; active-passive ventilation wall; latent thermal storage; mathematical model; solar greenhouse.

\section{Introduction}

The use of solar greenhouses for the production of fruits and vegetables is rapidly expanding in the cold weather conditions of Northern China (Bao, E., Cao, Y., Zou, Z. et al., 2018.). The specific feature of the North and Northwest China is the abundance of solar energy and low outdoor temperatures in a winter season. The passive solar greenhouses on their own in such regions cannot provide the thermal environment, necessary for the production of fruits and vegetables during winter periods. Coal-fired or electric air heaters are often used for auxiliary heating (Naijun, Z., Yaxiong, Y., Jinping, Y. et al., 2017 and Yildirim Nurdan, Bilir Levent, 2017).

Various energy conservation techniques, along with advanced methods of solar energy utilization for heating, are widely used to reduce the consumption of fossil fuels in greenhouses 
during winter periods. El-Maghlany et al. (2015) investigated oval greenhouses located at different latitudes (from 24 to $31.2^{\circ}$ ). It was found that the solar energy capture per square meter of the cultivated land reaches its maximum if the ellipse aspect ratio of the greenhouse is 4 . Chao et al. (2019) used EnergyPlus software to optimize the physical dimensions of the solar greenhouse for gaining more solar energy and reduction of the heat demand during winter periods. The results demonstrated that the heat load of the optimized greenhouse was $14.8 \%$ lower than that of the conventional greenhouse. Several studies reported that about $1 / 3$ of the solar radiation upon the transparent front roof of the solar greenhouse reaches the north wall surface and increases its temperature, which in turn rises the indoor air temperature by up to $10{ }^{\circ} \mathrm{C}$. This effect provides from 35 to $82 \%$ of the greenhouse heating requirement, depending on its location (Sethi and Sharma, 2008; Zhang et al., 2016; Wei et al., 2016). Investigations also confirmed that using a phase change material $(\mathrm{PCM})$ in the north wall of solar greenhouses in the northern hemisphere was an efficient way to improve the indoor thermal environment (Yataganbaba et al., 2017; Ramakrishnan et al., 2017). Berroug et al. (2011) used $\mathrm{CaCl}_{2} \cdot 6 \mathrm{H}_{2} \mathrm{O}$ as a PCM and analyzed its effects on the north wall of solar greenhouses. The study found that the north wall with the PCM had a greater heat storage capacity, leading to an increase of the indoor air temperature by 6-12 ${ }^{\circ} \mathrm{C}$ 。 However, due to the limitation in the thermal conductivity of phase change materials, the depth of the effective heat transfer into the wall is also restricted. This results in the inadequate performance of the wall as heat storage (Chao et al., 2018). Therefore, it is problematic to utilize solar energy resources by deploying only passive technologies to achieve the required indoor thermal environment in greenhouses, especially in winter nights.

Several studies described the application of solar water systems for greenhouse heating (Attar and Farhat, 2015; Sethi et al., 2013; Lazaar et al., 2015); Li et al., 2019) and studied the relationship between phase change material characteristics and optical performance of the solar concentrating system. Bazgaou et al. (2018) analyzed the performance of a rock-bed heating system in a conventional Canarian type greenhouse in Morocco. Results show that the temperature at night inside the greenhouse, equipped with the rock-bed, exceeds that of the control greenhouse by $2.6{ }^{\circ} \mathrm{C}$. The relative humidity was found to be $10 \%$ lower inside the heated greenhouse during the night-time. Kooli et al. (2015) constructed and built two similar greenhouses with a nocturnal 
shutter in Tunisia. The first one used a solar heating system with latent heat storage. The experimentally obtained results demonstrate that the difference between nocturnal temperatures inside greenhouses with and without shutter exceeds $2{ }^{\circ} \mathrm{C}$. Ntinas et al. (2014) described a mathematical model to predict the thermal efficiency of a novel hybrid solar energy saving system, located inside a heated greenhouse.

The use of complex active solar heating systems can improve the utilization of solar energy and effectively improve the thermal environment in greenhouses during the winter period. However, such systems increase the foot-print area and construction costs of greenhouses and reduce the area allocated for the cultivation of plants. For this reason, an active-passive heat storage ventilation wall with a PCM was developed at the Beijing University of Technology (Ling et al., 2014; Ling et al., 2016; Chao et al., 2018). The conducted investigations demonstrated that only when the new wall is coupled with a suitable solar air collector, the potential of it's integrated PCM heat storage is fully realized. A compound parabolic concentrator solar air collector is one of the most mature technologies in the field of solar collectors. This type of collector is of a simple structure and has a relatively small footprint and can heat the air up to $100^{\circ} \mathrm{C}$. Therefore these collectors were used in many applications, such as space heating, drying of agricultural and industrial products (Tao, et al., 2012; Zheng, et al., 2011). However, for further enhancement of the effectiveness of operation, the conventional compound parabolic solar concentrating air collector requires an accurate sun-tracking system, see Tong K., Yang L., Song J. et al., 2019 and Islam, M. T., Huda, N., Abdullah, A. B. et al., 2018). Without such the sun-tracking system, the annual and daily average efficiency of these collectors will be relatively low, which in turn negatively affects the economy and practicability of their application (Ma et al., 2019).

Acuna et al. (2017) developed a compound parabolic concentrator, which uses a single concentric tube as an absorber. Field experiments demonstrated that the design increased the collector's efficiency by $5 \%$, compared to a conventional collector. Zheng et al. (2016) designed a new type of serpentine compound parabolic concentrator and manufactured a prototype with dimensions of $1220 \times 1870 \times 100 \mathrm{~mm}$. The collector used water as a heat transfer fluid and achieved an efficiency of up to $65 \%$. Zou et al. (2016) proposed a small parabolic trough solar collector, which performed satisfactorily even at low-temperature conditions. The thermal efficiency of this 
collector was about $67 \%$ at the solar radiation of less than $310 \mathrm{~W} / \mathrm{m}^{2}$. Chamasa-ard et al. (2014) used a heat pipe evacuated tube inside a CPC solar collector and determined its thermal performance tests, conducted in accordance with ISO 9806-1 regulations, produced the efficiency of up to $78 \%$. Tolga Ural (2019) compared the thermodynamic performance of their new solar air collector and that of the flat-plate solar air collector (FP-SAC). Both collectors were tested simultaneously at identical conditions. The temperatures and the mass flow rate of heat transfer fluid and solar radiation were recorded. The results of this study indicated that the exergy efficiency of the new collector was $41 \%$, which is greater by $10 \%$ than that of the flat-plat SAC.

Numerous studies were also dedicated to the mathematical modelling of solar collectors. Manzolini et al. (2010) presented an innovative Parabolic Trough Thermodynamic Optimization (PATTO) code for predicting the overall performance of solar trough based concentrating systems. Hsieh et al. (1981) developed a model of heat transfer in compound parabolic concentrators. Their research created a foundation for following design optimization and heat transfer analysis studies for solar collectors. However, in the above model, authors assumed that such key components as glass cover, absorption tube wall and reflector were isothermal, which produced errors in operation predictions (Acuna, et al., 2017). Singh et al. (2012) studied theoretically and experimentally the mechanism of natural convection heat transfer in the cavity of trough collectors. Santos-Gonzalez et al. (2017) proposed a mathematical model of compound parabolic concentrators. The temperature difference between simulation results and real measurement in this study was within $\pm 0.2{ }^{\circ} \mathrm{C}$. Errors in theoretical predictions of efficiency and fluid pressure drop in pipes were found to be $6.4 \%$ and $10.7 \%$, respectively. Benoit (2016), using published data, analyzed the flow and heat transfer for heat transfer fluids in tubes on the basis of mass and energy balance equations. Relevant empirical correlations were proposed, applicable at certain conditions. Cao et al. (2016) used Fluent CFD software to analyze the influence of direct solar radiation intensity, heat transfer fluid inlet temperature and velocity on the efficiency and thermal performance of solar collectors. Hung et al. (2017) examined the heat transfer in a flat plate solar air collector and the obtained numerical results were compared to experimental data. The radiation flux, which varies during the day, was used as a boundary condition on the collector's absorbing surface. Wenye Lin, et al (2019) described the mathematical model and theoretical results from the 
performance evaluation of solar air collectors (SACs) with corrugated absorbers for indoor space heating. The study demonstrated that the surface absorptance and opening angle of the corrugated absorber were the most significant design variables governing the thermal efficiency of SACs.

Overall, results of analyzed publications demonstrate that previous studies mainly concentrated on the evaluation of the performance of the solar collectors as a separate component, with insufficient consideration of their operation as an integral part of heating system and to the adaption of their design configuration to the technical requirements and heating demand of the heating system.

In this study, a novel multi-surface solar air collector with double-receiver tubes (MSC-DRT) is proposed, which does not require a sun-tracking mechanism, has an increased concentration ratio and solar rays convergence rate and lower thermal losses, compared to parabolic trough, evacuated tube, and flat-plate collectors. The laboratory and full-scale prototypes of the proposed novel design were manufactured, which were experimentally tested in laboratory conditions and as a part of the existing active-passive heating system of the greenhouse, which has the ventilation wall with a latent heat thermal storage on its inner side, facing the sun. Such the active-passive heating system with the ventilation wall and latent heat storage had been previously proposed, designed and tested by researchers at the Beijing University of Technology. Tests were run to evaluate the performance of the full-scale prototype of the novel design of the collector and greenhouse during two winter months (December and January). Results from experimental investigations demonstrate that the novel solar collector provides considerable fossil fuel savings by partially meeting heating demand of the greenhouse with the active-passive heating system, which has the ventilation wall with a latent heat storage, located in the Beijing Region. The lumped parameter mathematical model of the proposed collector was developed, and the comparison of simulation results and experimental data demonstrates its high accuracy in the prediction of the collector performance. The model was used to study the influences of outdoor meteorological parameters, air velocity in the receiver tubes and their length on the thermal performance of the collector. This data was used to propose rational design parameters and air velocity for the future improved design of the collector. The improved design of the collector will make it possible to provide even a greater fraction of heat demand by the greenhouse and reduce 
the carbon footprint of the agricultural industry in regions with cold climate.

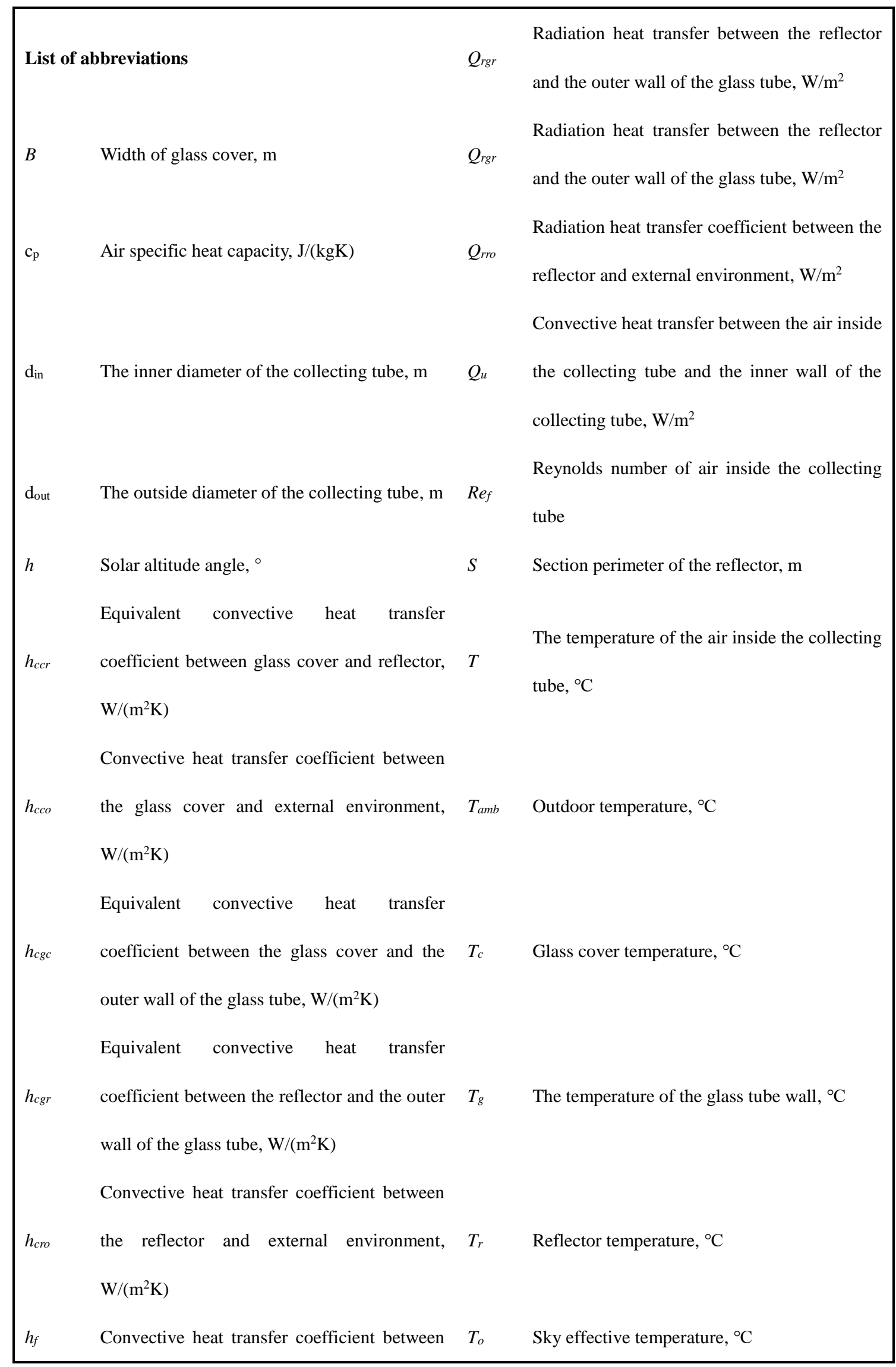


air and the inner wall of the glass tube,

$\mathrm{W} /\left(\mathrm{m}^{2} \mathrm{~K}\right)$

Radiation heat transfer coefficient between

$h_{\text {rco }} \quad$ the glass cover and external environment,

Air kinematic viscosity, $\mathrm{m}^{2} / \mathrm{s}$

$\mathrm{W} /\left(\mathrm{m}^{2} \mathrm{~K}\right)$

Radiation heat transfer coefficient between

$h_{r c r}$ glass cover and external environment, $v_{f}$ Outdoor wind speed, $\mathrm{m} / \mathrm{s}$

$\mathrm{W} /\left(\mathrm{m}^{2} \mathrm{~K}\right)$

Radiation heat transfer coefficient between

$h_{r g c} \quad$ the glass cover and the outer wall of the glass

$V_{o} \quad$ Air velocity inside the collecting tube, $\mathrm{m} / \mathrm{s}$ tube, $\mathrm{W} /\left(\mathrm{m}^{2} \mathrm{~K}\right)$

Radiation heat transfer coefficient between the reflector and the outer wall of the glass

$X m_{i} \quad$ Actual values tube, $\mathrm{W} /\left(\mathrm{m}^{2} \mathrm{~K}\right)$

Radiation heat transfer coefficient between

$h_{\text {rro }}$ the reflector and external environment,

$X_{\text {mave }} \quad$ Actual mean values in each time $\mathrm{W} /\left(\mathrm{m}^{2} \mathrm{~K}\right)$

Total solar radiation density emitted vertically

I into the surface of glass cover, $\mathrm{W} / \mathrm{m}^{2}$

$X p_{i} \quad$ Simulate values

IA Error analysis index

$X_{\text {pave }} \quad$ Simulate mean values in each time

Direct-beam solar radiation density emitted

$I_{D} \quad$ vertically into the surface of glass cover,

\section{Greek letters}

$\mathrm{W} / \mathrm{m}^{2}$

Diffuse solar radiation density emitted

IDV vertically into the surface of glass cover, $\alpha_{a}$ The absorption rate of the heat absorber $\mathrm{W} / \mathrm{m}^{2}$

Ground reflected radiation density emitted

$I_{R V} \quad$ vertically into the surface of glass cover, $\alpha_{c}$ The absorption rate of the glass cover $\mathrm{W} / \mathrm{m}^{2}$ 


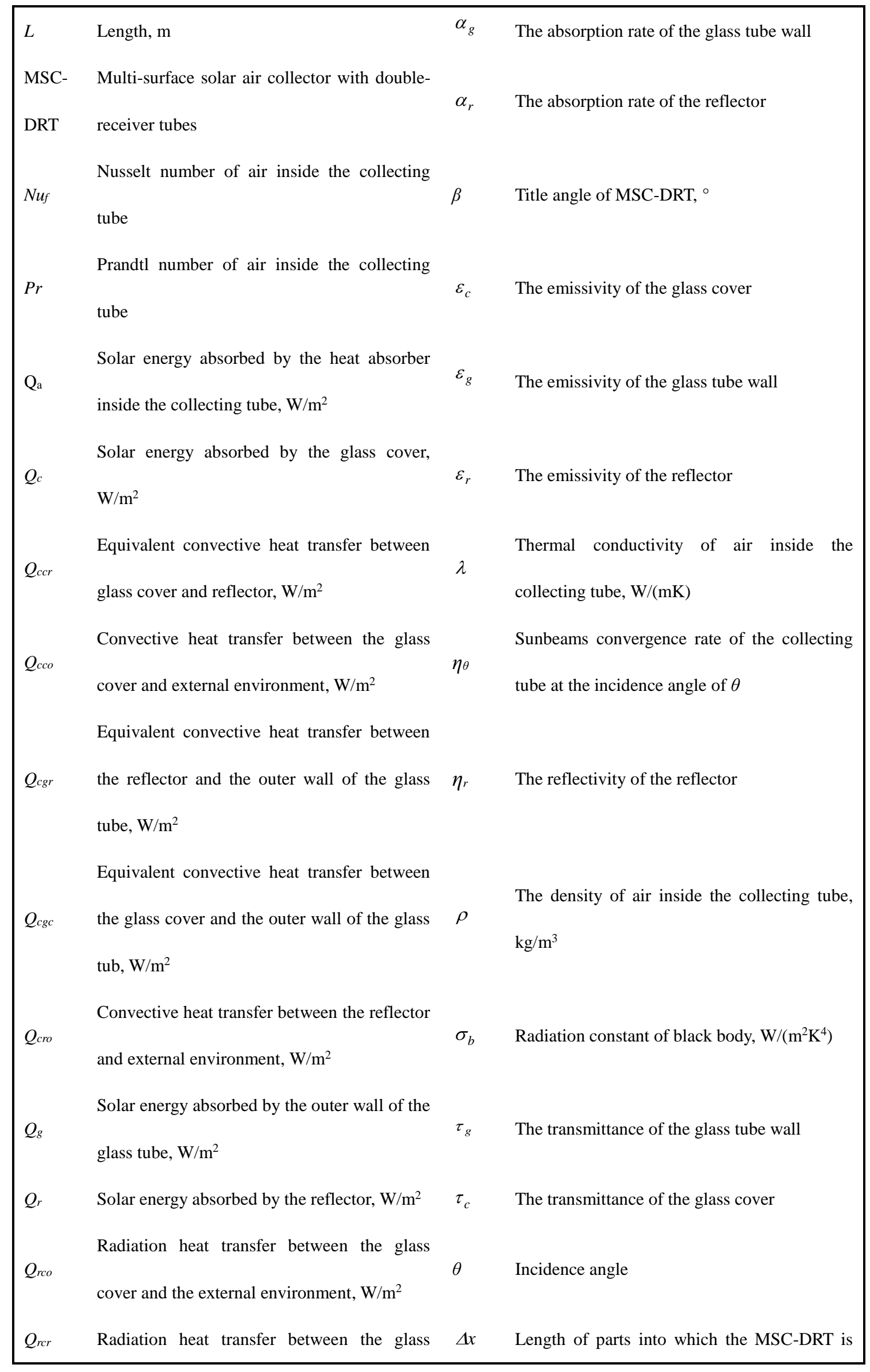




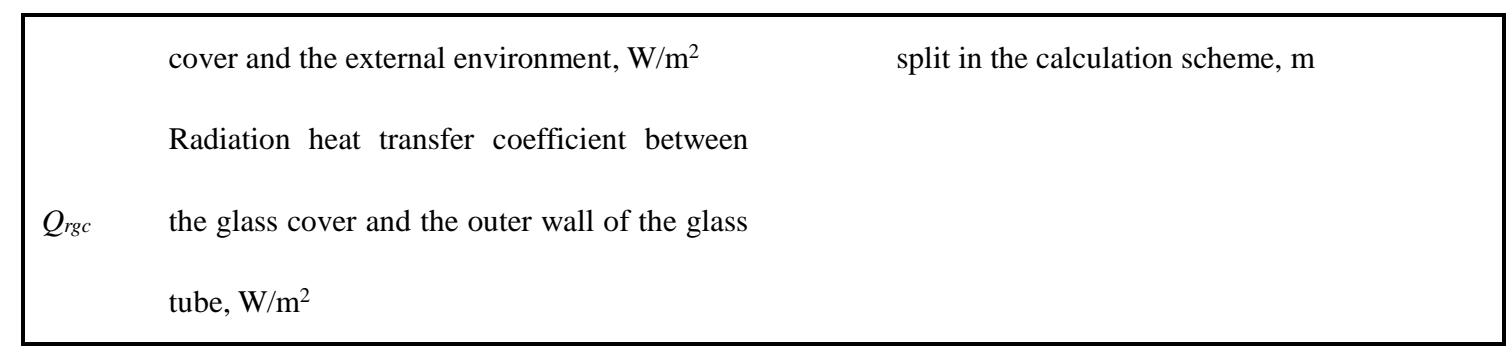

\section{Description of the design of the novel solar air collector and greenhouse with}

passive-active ventilation wall and latent heat storage

\subsection{Description of the new compound parabolic concentrator}

Fig. 1a shows the three-dimensional schematic of the developed novel MSC-DRT and Fig. 1b presents its cross-section with an indication of its dimensions. The main components of the novel MSC-DRT include a glass cover with the high transmittance, multi-surface reflector with side and bottom surfaces and two receiving tubes, see Fig. 1a. Geographically the design was optimized for application in Northern China. Various configurations were considered, including using more than two receiving tubes (with smaller diameters) but, overall, the two-receiver tube configuration shown in Fig. 1, demonstrated the best combination of the cost, efficiency and productivity parameters.

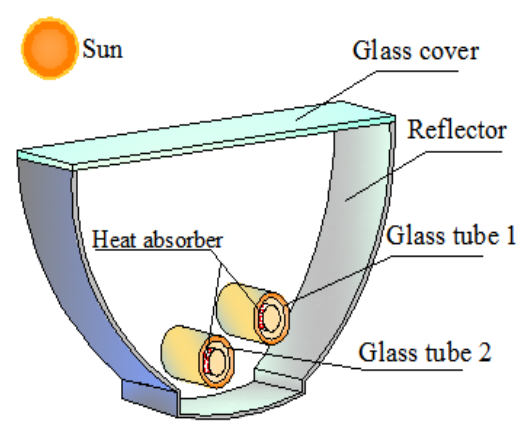

(a) The three-dimensional schematic

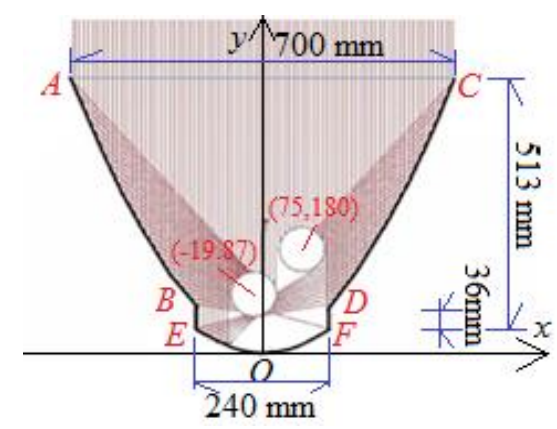

(b) The cross-section of the MSC-DRT with an indication of its dimensions

Fig. 1 The three-dimensional schematic of the developed novel MSC-DRT and its cross-section with an indication of its dimensions. 
Table 1 Materials of collector components, component dimensions and optical properties of materials

\begin{tabular}{|c|c|c|c|c|}
\hline & \multicolumn{2}{|c|}{ Receiver tubes } & \multirow{2}{*}{ Reflector } & \multirow{2}{*}{ Glass cover } \\
\hline & Heat absorber & Glass tube & & \\
\hline Material & $\begin{array}{l}\text { Black chromium coated } \\
\text { aluminum mesh }\end{array}$ & $\begin{array}{l}\text { Low-iron } \\
\text { glass }\end{array}$ & $\begin{array}{l}\text { Polished } \\
\text { aluminum alloy }\end{array}$ & $\begin{array}{l}\text { Low-iron } \\
\text { glass }\end{array}$ \\
\hline Width (m) & - & - & - & 0.7 \\
\hline Thickness (m) & - & - & 0.0008 & 0.005 \\
\hline $\begin{array}{l}\text { Inner/Outer } \\
\text { diameter (m) }\end{array}$ & $0.08 /-$ & $0.097 / 0.103$ & - & - \\
\hline Reflectivity & - & - & 0.91 & - \\
\hline Transmittance & - & 0.87 & - & 0.87 \\
\hline Absorptivity & 0.90 & 0.02 & 0.09 & 0.01 \\
\hline Emissivity & - & 0.86 & 0.03 & 0.9 \\
\hline
\end{tabular}

In order to improve the concentration and sunbeams convergence ratio of the MSC-DRT, the multi-surface reflector was designed with the off-axis location of the receiver tubes. Two tubes were used to split the airflow and increase the heating surface/volume ratio. Additionally, such the design allows the enhancement of the convergence rate of the direct and reflected sunbeams over the wide range of incidence angles. The three parabolic curves $A B, C D$ and $E O F$, which make up the reflecting surfaces of the collector, can be described in the coordinate system shown in Fig. $1 \mathrm{~b}$ as:

$$
\begin{aligned}
& A B: \quad y=\frac{1}{0.92}(x+0.23)^{2} \\
& C D: \quad y=\frac{1}{0.92}(x-0.23)^{2} \\
& \text { EOF: } \quad y=\frac{x^{2}}{160}
\end{aligned}
$$

The concentrating ratio $\mathrm{C}$ is the ratio of the collector aperture and heat absorption areas. For the described dimensions of the concentrating collector, $\mathrm{C}$ is about 1.4.

Fig. 2 demonstrates the design details of the receiver tube. The receiver tube has a glass cover tube with a concentric heat absorber tube inside. The heat absorber tube is made of the aluminum 
mesh (the diameter of wires is $0.7 \mathrm{~mm}$ and mesh size is 10 ), which is coated with a thin layer of black chromium for improving solar energy absorption effect. The perforated surface of the heat receiver intensifies turbulence in airflow passing through the receiver tube, leading to an increase of heat transfer from the heat absorber tube to the airflow.
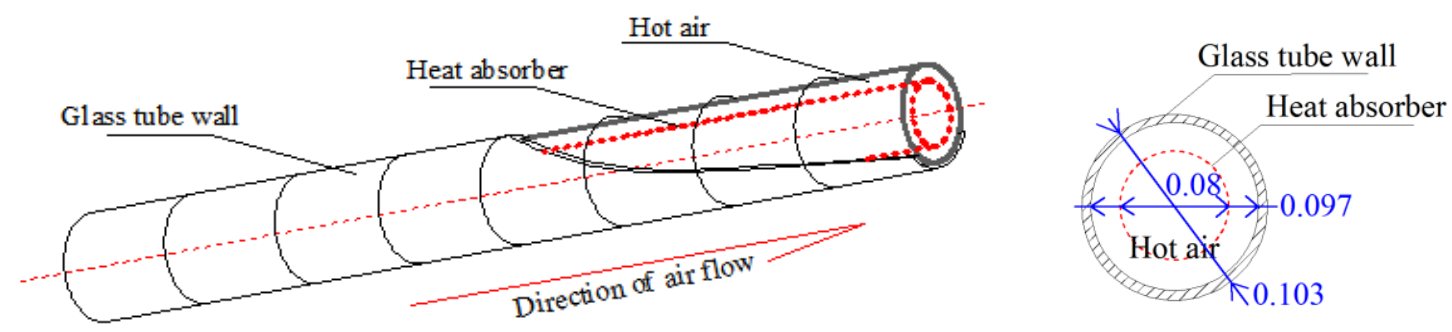

Fig. 2 Design details of the receiver tube.

The experimental thermal performance of the 2-m laboratory-scale prototype of the proposed MSC-DRT was compared to that of the traditional compound parabolic trough collector of the same length and with one receiver tube for conditions when the solar radiation intensity at noon was $920 \mathrm{~W} / \mathrm{m}^{2}$, and the daily cumulative solar energy was $20 \mathrm{MJ} / \mathrm{m}^{2}$. The air-flow rates in each of the tubes of the MSC-DRT collector and that in the traditional collector were identical. Experimental results obtained for both the collectors show that in the MSC-DRT collector the instantaneous heat gain and efficiency per unit area were increased by $16 \%$ and $9 \%$, respectively.

LightTools software was used to select the positions of the two receiver tubes inside of the multi-face collector so as to maximize the convergence rate of sunbeams reflected from the side and bottom surfaces of the collector. These simulations demonstrate that the proposed design exhibits high optical performance for incidence angles between $-20^{\circ}$ and $+20^{\circ}$, see Fig. 3. The LighTools modelling shows that if the incidence angle varies within the above range then in the proposed design the average value of sunbeams convergence rate for a single receiver tube 1 is about 0.4 and the total value of the sunbeams convergence rate for both the receiving tubes varies between 0.74 and 1 with its average value of 0.90 , see Fig. 4 . 


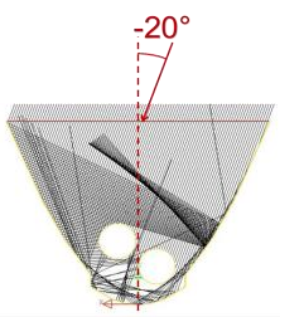

Incidence angle is

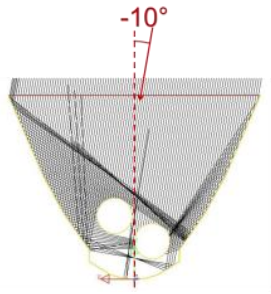

Incidence angle is

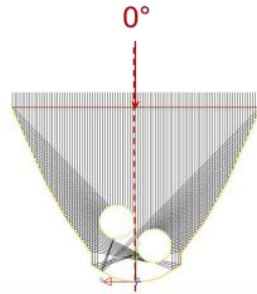

Incidence angle is

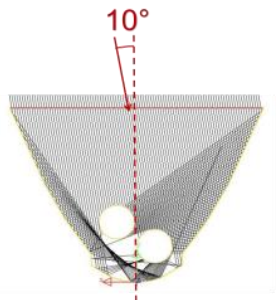

Incidence angle is

$+10^{\circ}$

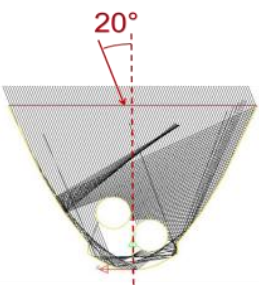

Incidence angle is

$+20^{\circ}$

Fig. 3 Results of solar rays tracing using LightTools optical software

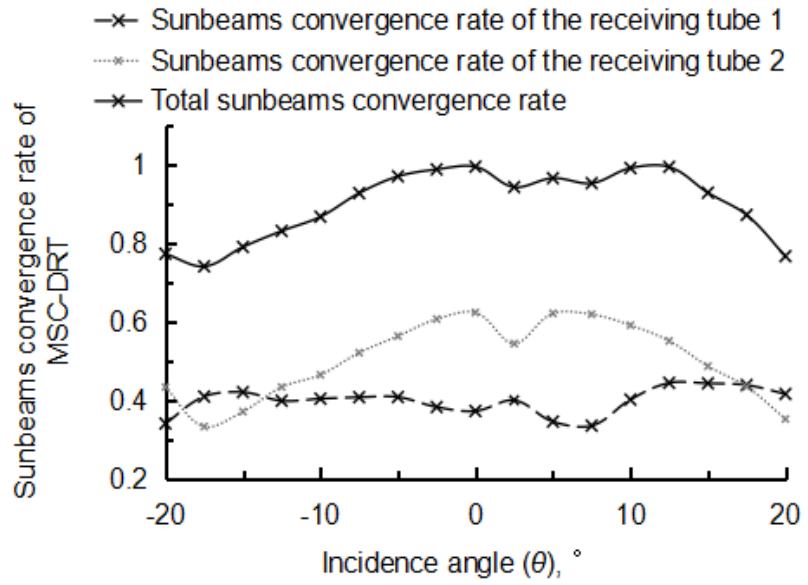

Fig. 4 Variation of sunbeams convergence rate as a function of the incidence angle.

\subsection{Description of the greenhouse with active-passive ventilation wall and latent thermal} storage

The manufactured full-scale prototype of the novel MSC-DRT was integrated into the greenhouse with active-passive ventilation and latent heat storage located in the Beijing Region. Fig. 5 shows its design (a) and airflow piping (b). The MSC-DRT is installed on the top back-wall behind the back-roof of the greenhouse.

The collector has a single common inlet and single outlet manifolds for two receiver tubes. The airflow in the inlet manifold is split between two receiver tubes, which are connected to the outlet manifold. The details of the design of the greenhouse were described in (Chen et al., 2017) and (Haoshu Ling et al., 2019). The back-wall (3) of the greenhouse is made of the cement block and bricks with internal vertical air channels (5) for the heated airflow. 


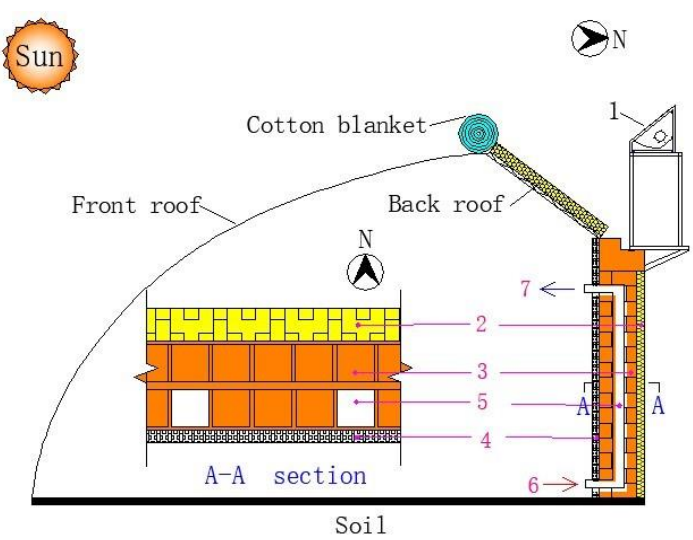

a. Structure diagram of the solar greenhouse with the

active-passive ventilation system and latent

heat storage with the installed MSC-DRT

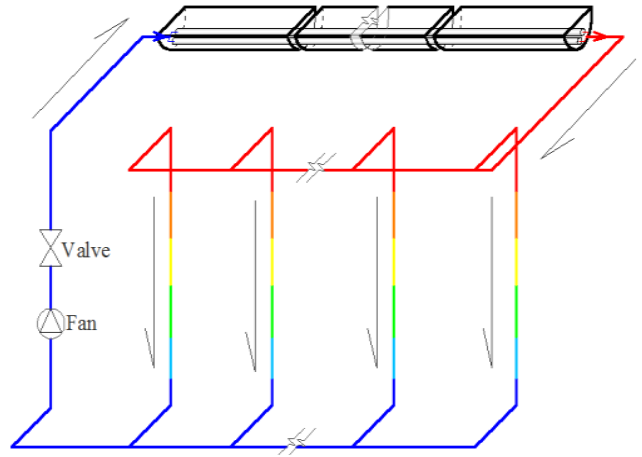

b. Schematic diagram of the active-passive

heat storage ventilation system with the

MSC-DRTs

Fig. 5 The novel MSC-DRT integrated into the greenhouse with an active-passive ventilation wall and latent thermal storage.

1 - multi-surface solar air collector with double-receiver tubes (MSC-DRT); 2 - Insulation layer; 3 - Cement block/brick wall with vertical air channels; 4 - Phase change material layer; 5 - Vertical air channels; 6 Low-temperature air to MSC-DRT; 7 -Hot air from MSC-DCTs.

The wall has the insulation layer (2) on its external side and the phase change material layer (4) on its surface, facing the inner greenhouse space. Air, heated in the MSC-DRT (1), is directed into the vertical channels of the wall through the inlet 6 and leaves through the exit (7) to be circulated back to the collector. The phase change material layer is made of the GH-20 composite phase change material wallboards as described in (Haoshu Ling et al., 2019). The melting point of the phase change material is $20^{\circ} \mathrm{C}$. During the day, the back-wall with the phase change material layer is exposed to the solar radiation (incoming mainly through the front-roof of the greenhouse). This energy is accumulated by both the phase change material layer and back-wall (passive heating). The latter is also additionally heated with airflow from the MSC-DRT, driven by air fan (active heating). The accumulated heat is released into the indoor environment during nighttime through both heat radiation and convection mechanisms. The volumetric flow rate of air in the developed MSC-DRT is more than $0.028 \mathrm{~m}^{3} / \mathrm{s}$. The additional advantages of the collector include small footprint, required for installation, relatively small weight and height, which eliminates the problem with the shading of neighboring greenhouses, which are usually built one after another in 
rows.

\subsection{The MSC-DRT thermal performance parameters}

The two main parameters to evaluate the performance of the MSC-DRT are the outlet air temperature and its efficiency.

The outlet temperature depends on outdoor meteorological conditions, air velocity in the receiver tubes and their length:

$$
T=f\left(I, T_{a m b}, v_{f}, V_{o}, L\right)
$$

If the outlet air temperature in the MSC-DRT is not sufficiently high, then it will be problematic to transfer this thermal energy to the mass of the wall due to the low temperature difference. If this temperature exceeds some critical point, then utilization of heat gains by the MSC-DCT in the active-passive heat storage ventilation system is also a challenging task.

The effective heat gain and efficiency of the MSC-DRT can be calculated as

$$
\begin{gathered}
Q_{o}=\frac{\rho c_{p} \pi d_{i n}^{2} V_{o}\left(T-T_{i n}\right)}{2} \\
\eta=\frac{Q_{o}}{I B L}
\end{gathered}
$$

\section{Mathematical model of the MSC-DRT}

\subsection{Calculation scheme and assumptions}

In the calculation scheme of the MSC-MDR, this is split along its length into a number of small control elements with the length of the element equal to $d x$, see Fig. 6. The mathematical model of the MSC-DRT is made of a system of algebraic equations of energy balance written for all elements of the glass cover, reflector, glass receiver tubes, heat absorber and air in the calculation scheme, see Fig. 7. The code was developed in MATLAB software environment to solve these equations. 


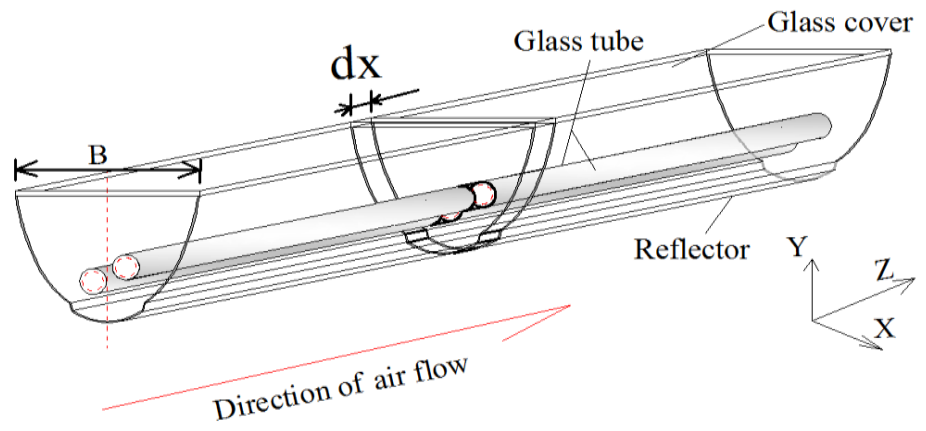

Fig. 6 Calculation scheme of the MSC-DRT.

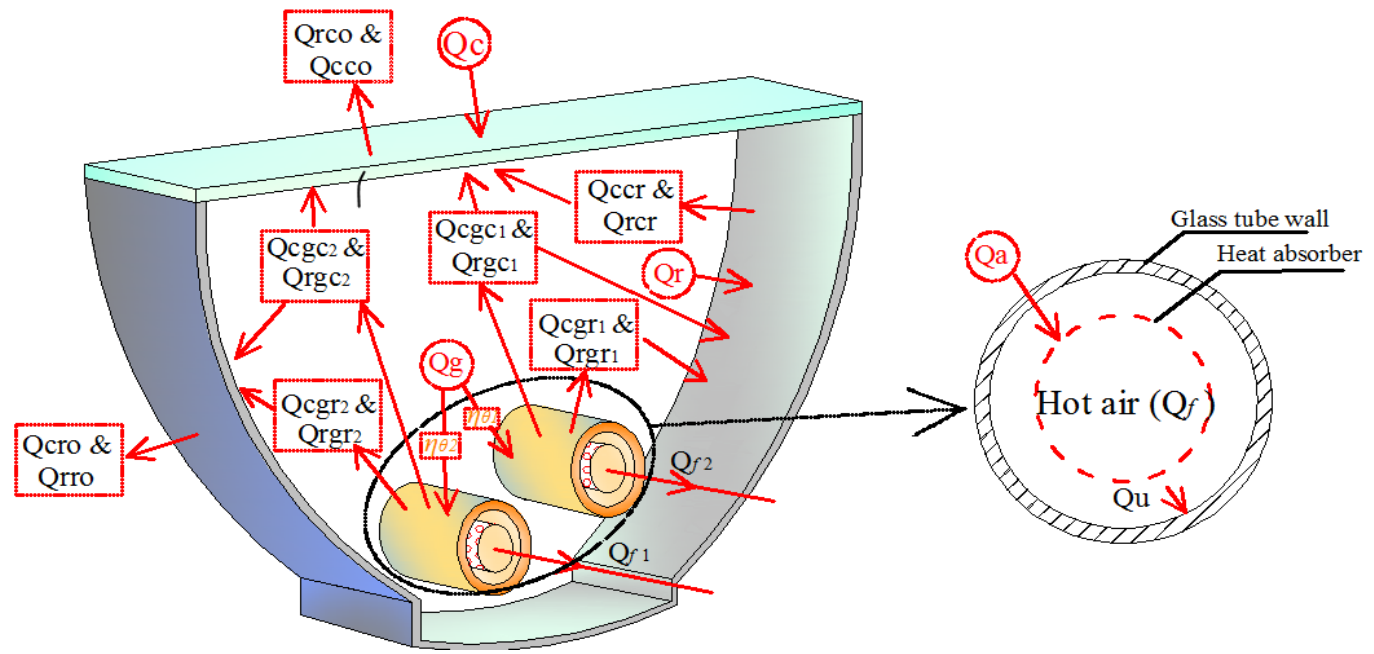

(a)

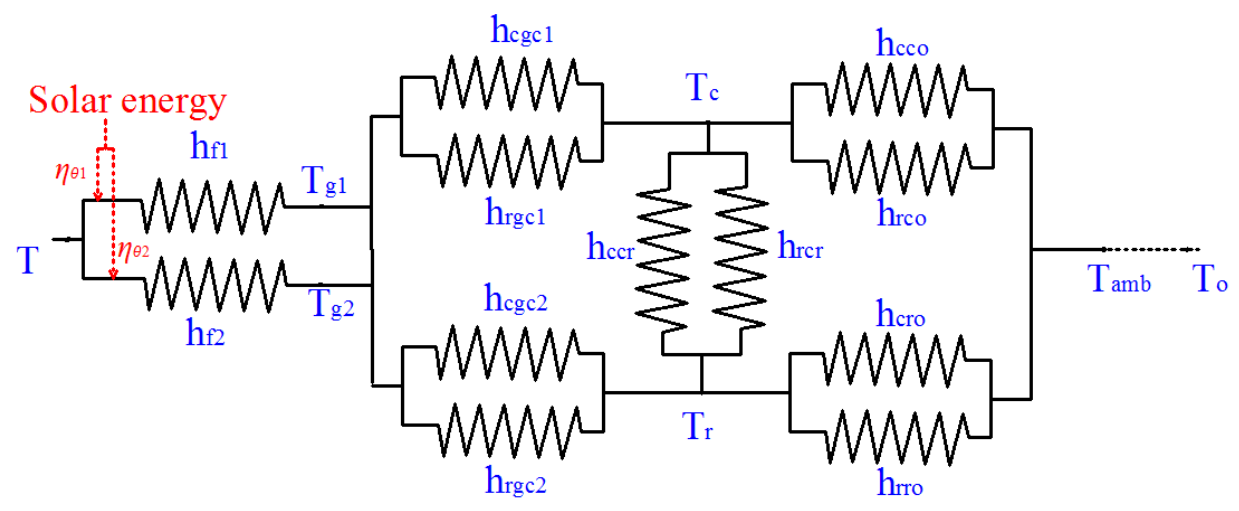

(b)

Fig. 7 Energy balance scheme for the ith-element of the MSC-DRT (a) and energy flows between components.

The following assumptions were made in the process of solution of the system of equations:

- The airflow and heat transfer are steady-state processes;

- $\quad$ The heat conduction in each element along its length is negligible;

- Adiabatic boundary conditions are applied at the two ends of the MSC-DCT 
receiver tubes and heat absorber;

- The inlet air temperature and air velocity in each collecting tube are identical;

- The air velocity inside receiver tubes are equal and constant along their lengths;

- The convection heat transfer between the collector elements and air in the cavity under the cover glass are considered as the equivalent convection heat transfer between corresponding elements (Santos-Gonzalez et al., 2017);

- The heat absorber inside the receiver is considered to be an internal heat source for air;

- The heat transfer between receiving tubes does not affect the total heat gain of the MSC-DRT and therefore is neglected;

- The surface of the receiver tube is much smaller, compared to that of the reflector and the glass cover and therefore the influence of the relative positions of the two receiver tubes on the heat transfer between them and the reflector and glass cover is neglected;

- The air volume in receiver tubes are identical, and the surface area of the glass tubes is much smaller than that of the reflector and the glass cover, and therefore the heat transfer between two tubes is negligible, and distribution of intercepted solar energy has insignificant influence on the total effective heat gains and losses.

The energy balance equations for elements of the MSC-DRT can be derived by applying the above assumptions.

\subsection{Energy balance for the $i^{\text {th }}$ element of the glass cover}

As shown in Fig. 7, the energy flows in the $i^{\text {th }}$ element of the glass cover include the solar energy absorbed by the glass cover $\left(Q_{c}\right)$; the equivalent convective $\left(Q_{c c r}\right)$ and radiative $\left(Q_{r c r}\right)$ heat transfers between the glass cover and reflector; the equivalent convective $\left(Q_{c g c 1}(2)\right)$ and radiative $\left(Q_{r g c 1}(2)\right)$ heat transfers between the outer wall of the glass tubes 1 and 2 and the glass cover; the convective $\left(Q_{c c o}\right)$ and the radiation $\left(Q_{r c o}\right)$ heat transfers between the glass cover and external environment. Therefore the energy balance equation for the $i^{\text {th }}$ element of the glass cover can be written as

$$
Q_{c}+Q_{c c o}+Q_{r c o}-Q_{c g c 1}-Q_{r g c 1}-Q_{c g c 2}-Q_{r g c 2}+Q_{c c r}+Q_{r c r}=0
$$


Solar energy absorbed by the glass cover $\left(Q_{c}\right)$ can be determined as

$$
Q_{c}=\alpha_{c} I B \Delta x
$$

where $I$ is the total irradiance upon the surface of the glass cover, including the direct solar radiation $\left(I_{D}\right)$, scattered solar radiation $\left(I_{D V}\right)$ and radiation reflected from the surrounding ground $\left(I_{R V}\right)$. These three components of solar radiation can be calculated by deploying a series of equations described in (Yuexia Lv et al., 2018).

The equivalent convective heat transfer $\left(Q_{c c r}\right)$ between the glass cover and reflector can be calculated as

$$
Q_{c c r}=h_{c c r}\left(T_{r}-T_{c}\right) B \Delta x
$$

where $h_{c c r}$ is the equivalent convective heat transfer coefficient between the reflector and cover. In calculations, this heat transfer coefficient was assumed to be $5 \mathrm{~W} /\left(\mathrm{m}^{2} \mathrm{~K}\right)$, as reported in several studies, e.g. (Santos-Gnzalez et al., 2017) and (Hsieh, 1981).

The radiative heat transfer $\left(Q_{r c r}\right)$ between the glass cover and reflector is calculated as

$$
Q_{r c r}=h_{r c r}\left(T_{r}-T_{c}\right) B \Delta x
$$

where $h_{r c r}$ is the radiative heat transfer coefficient between the reflector and cover:

$$
h_{r c r}=\frac{\sigma_{b}\left(\left(T_{c}+273.15\right)^{2}+\left(T_{r}+273.15\right)^{2}\right)\left(T_{r}+T_{c}+5463\right)}{\frac{1}{\varepsilon_{c}}+\left(\frac{1}{\varepsilon_{r}}-1\right) \times \frac{B}{S}}
$$

The convective heat transfer $\left(Q_{c c o}\right)$ between the glass cover and external environment can be calculated as

$$
Q_{c c o}=h_{c c o}\left(T_{a m b}-T_{c}\right) B \Delta x
$$

where $h_{c c o}$ is the convective heat transfer coefficient between the glass cover and the external environment (Acuna et al., 2017):

$$
h_{c c o}=5.7+3.8 v_{f}
$$

The radiation heat transfer $\left(Q_{r c o}\right)$ between the glass cover and external environment is determined as

$$
Q_{r c o}=h_{r c o}\left(T_{o}-T_{c}\right) B \Delta x
$$

where $h_{r c o}$ is the radiative heat transfer coefficient between the glass cover and external environment and calculated as

$$
h_{r c o}=\varepsilon_{c} \sigma_{b}\left(\left(T_{c}+273.15\right)^{2}+T_{o}^{2}\right)\left(T_{c}+273.15+T_{o}\right)
$$


In Eq. (15), $T_{o}$ is the sky effective temperature (Santos-Gnzalez et al., 2017):

$$
T_{o}=0.055 \mathcal{2}_{a m b} 1.5
$$

The equivalent convective heat transfer $\left(Q_{c g c}\right)$ between the outer wall of the glass tube and glass cover can be determined as

$$
Q_{c g c}=h_{c g c}\left(T_{c}-T_{g}\right) B \Delta x
$$

where $h_{c g c}$ is the convective heat transfer coefficient between the outer wall of the glass tube and glass cover (Santos-Gnzalez et al., 2017):

$$
h_{c g c}=3.25+0.0085 \frac{T_{g}-T_{c}}{2 d_{\text {out }}}
$$

The radiative heat transfer $\left(Q_{r g c}\right)$ between the outer wall of the glass tube and glass cover is

$$
Q_{r g c}=h_{r g c}\left(T_{c}-T_{g}\right) B \Delta x
$$

where $h_{r c o}$ is the radiative heat transfer coefficient between the outer wall of the glass tube and glass cover defined as

$$
h_{r g c}=\frac{\sigma_{b}\left(\left(T_{g}+273.15\right)^{2}+\left(T_{c}+273.15\right)^{2}\right)\left(T_{g}+T_{c}+5463\right)}{\left(\frac{1}{\varepsilon_{c}}-1\right)+\frac{B}{\pi d_{\text {out }}}+\left(\frac{1}{\varepsilon_{g}}-1\right) \times \frac{B}{\pi d_{\text {out }}}}
$$

\subsection{Energy balance equation for the $i^{\text {th }}$ element of the reflector}

As shown in Fig. 7, when considering the $i^{\text {th }}$ element of the reflector, energy flows include the solar energy absorbed by the reflector $\left(Q_{r}\right)$; the equivalent convective $\left(Q_{c c r}\right)$ and the radiative $\left(Q_{r c r}\right)$ heat transfers between the glass cover and reflector; the equivalent convective $\left(Q_{c g r 1}(2)\right.$ and radiative $\left(Q_{r g r 1}\right.$ (2) heat transfers between the outer wall of the glass tubes 1 or 2 and reflector; the convective $\left(Q_{c r o}\right)$ and radiative $\left(Q_{r r o}\right)$ heat transfers between the reflector and external environment. The energy balance equation for the $i^{\text {th }}$ element of the reflector can be written as

$$
Q_{r}+Q_{c r o}+Q_{r r o}-Q_{c g r 1}-Q_{r g r 1}-Q_{c g r 2}-Q_{r g r 2}-Q_{c c r}-Q_{r c r}=0
$$

The solar energy absorbed by the reflector $\left(Q_{r}\right)$ can be calculated as

$$
Q_{r}=\tau_{c} \alpha_{r} I B \Delta x
$$

The equivalent convective heat transfer $\left(Q_{c g r}\right)$ between the outer wall of glass tube 1 or 2 and reflector can be determined as

$$
Q_{c g r}=h_{c g r}\left(T_{r}-T_{g}\right) S \Delta x
$$


where $h_{c g r}$ is the convective heat transfer coefficient between the outer wall of glass tube 1 or 2 and reflector (Santos-Gnzalez et al., 2017):

$$
h_{c g r}=3.25+0.0085 \frac{T_{g}-T_{r}}{2 d_{\text {out }}}
$$

The radiative heat transfer $\left(Q_{r g r}\right)$ between the outer wall of the glass tube the and reflector is

$$
Q_{r g r}=h_{r g r}\left(T_{r}-T_{g}\right) S \Delta x
$$

where $h_{r g r}$ is the radiative heat transfer coefficient between the outer wall of the glass tube and the reflector, which is determined as

$$
h_{r g r}=\frac{\sigma_{b}\left(\left(T_{g}+273.15\right)^{2}+\left(T_{r}+273.15\right)^{2}\right)\left(T_{g}+T_{r}+5463\right)}{\left(\frac{1}{\varepsilon_{r}}-1\right)+\left(\frac{1}{\varepsilon_{g}}-1\right) \frac{S}{\pi d_{\text {out }}}}
$$

The convective heat transfer $\left(Q_{c r o}\right)$ between the reflector and external environment can be determined as

$$
Q_{c r o}=\mathrm{h}_{c r o}\left(T_{a m b}-T_{c}\right) S \Delta x
$$

where $h_{\text {cro }}$ is the convective heat transfer coefficient between the reflector and external environment (Acuna et al., 2017):

$$
h_{\text {cro }}=5.7+3.8 \mathrm{v}_{f}
$$

The radiation heat transfer $\left(Q_{r r o}\right)$ between the reflector and external environment can be calculated as

$$
Q_{r r o}=h_{r r o}\left(T_{o}-T_{r}\right) S \Delta x
$$

where $h_{r r o}$ is the radiative heat transfer coefficient between the reflector and external environment, determined as

$$
h_{r r o}=\varepsilon_{r} \sigma_{b}\left(\left(T_{r}+273.15\right)^{2}+T_{o}^{2}\right)\left(T_{r}+T_{o}+273.15\right)
$$

\subsection{Energy balance equation for the $i^{\text {th }}$ element of the glass tube}

When considering the $i^{\text {th }}$ element of the glass tubes 1 and 2, see Fig. 7, the energy flows include the solar energy absorbed by the glass tubes $1\left(Q_{g 1}\right)$ and $2\left(Q_{g 2}\right)$; the equivalent convective $\left(Q_{c g r 1(2)}\right)$ and radiative $\left(Q_{r g r 1(2)}\right)$ heat transfers between the outer wall of glass tubes 1 or 2 and the reflector; the equivalent convective $\left(Q_{c g c 1}\right.$ (2) $)$ and radiative $\left(Q_{r g c 1}\right.$ (2) $)$ heat transfers between the outer wall of glass tubes 1 or 2 and the glass cover; the convective $\left(Q_{u 1(2)}\right)$ heat transfer between air inside the glass tubes 1 or 2 and the inner wall of the glass tube 1 or 2 . The energy balance 
equation for the $i^{\text {th }}$ element of the glass tubes 1 and 2 can be written as

$$
Q_{g 1(2)}+Q_{u 1(2)}+Q_{c g r 1(2)}+Q_{r g r 1(2)}+Q_{c g c 1(2)}+Q_{r g c 1(2)}=0
$$

The solar energy absorbed by the glass tubes $1\left(Q_{g 2}\right)$ and $2\left(Q_{g 2}\right)$ are determined as

$$
\begin{aligned}
& Q_{g 1}=\tau_{c} \eta_{r} \eta_{\theta 1} \alpha_{g} I B \Delta x \\
& Q_{g 2}=\tau_{c} \eta_{r} \eta_{\theta 2} \alpha_{g} I B \Delta x
\end{aligned}
$$

Since the air velocities inside both glass receiver tubes are identical, the convective heat transfer between the glass tube wall and air inside the glass tube is calculated for both tubes using the same following equation:

$$
Q_{u}=h_{f}\left(T-T_{g}\right) \pi d_{i n} \Delta x
$$

where $h_{f}$ is the convective heat transfer coefficient between the glass tube's wall and air inside, which can be determined as

$$
h_{f}=\lambda N u_{f} / d_{i n}
$$

Here

$$
N u_{f}=0.0214\left(R e_{f}^{0.8}-100\right) P_{r}^{0.4}\left(1+\left(\frac{d_{i n}}{L}\right)^{2 / 3}\right)\left(\frac{T}{T_{g}}\right)^{0.45}
$$

where

$$
R e_{f}=V_{0} d_{i n} / v
$$

Eqs. (35) and (36) are valid if $0.6<P_{r}<1.5 ; 0.5<T / T_{\mathrm{g}}<1.5 ; 2300<R e_{f}<10^{6}$ (Gnieinski, V., 1976).

\subsection{Energy balance equation for the $i^{\text {th }}$ element of air with the corresponding element of the heat absorber}

When considering air inside the $i^{\text {th }}$ element of the receiver tube, see Fig. 7, the part of the absorbed solar energy increases the internal energy of air with the other part being transferred to the glass tube's wall by the convective heat transfer:

$$
\left(\rho_{i} c_{p} \pi\left(\frac{d_{i n}}{2}\right)^{2} V_{O} T_{i}-\rho_{i-1} c_{p} \pi\left(\frac{d_{i n}}{2}\right)^{2} V_{O} T_{i-1}\right)=Q_{a}-Q_{u}
$$

The solar energy absorbed by air with the heat absorber inside the glass tubes 1 or 2 can be 
determined as

$$
\begin{aligned}
Q_{a 1} & =\tau_{c} \eta_{r} \eta_{\theta 1} \tau_{g} \alpha_{a} I B \Delta x \\
Q_{a 2} & =\tau_{c} \eta_{r} \eta_{\theta 2} \tau_{g} \alpha_{a} I B \Delta x
\end{aligned}
$$

In calculations, the dependence of the $\operatorname{Pr}$ number and physical parameters of air were taken into account. For that purpose experimental data by (Zhang Ximin et al., 2007) was interpolated by fitting the corresponding curves (with the accuracy of $\mathrm{R}^{2}>0.9$ ):

$$
\begin{gathered}
\left.P_{r}=-0.000185 T-273.15\right)+0.7073 \\
v=[0.1026(T-273.15)+13.04] \times 10^{-6} \\
\rho=9.55(T-273.15) \times 10^{-6}-0.0044(T-273.15)+1.29
\end{gathered}
$$

Eqs. (41)-(43) are valid in the range of $-20{ }^{\circ} \mathrm{C}<\mathrm{T}<160{ }^{\circ} \mathrm{C}$.

\subsection{Solution procedure}

The system of the algebraic equations, describing airflow and heat transfer in the MSC-DRT, was solved in MATLAB, following the algorithm of calculations presented in Fig. 8. Information on the design, physical and operating parameters of the MSC-DRT and actual weather data are used as input data. The outcomes of the numerical solution of the system of governing equations in the mathematical model are the outlet air temperature, effective heat gains and efficiency for the MSC-DRT. The solution convergence criterion was selected as the difference of values of the outlet air temperature being equal to $0.01{ }^{\circ} \mathrm{C}$. The dependence of results on the value of the deployed time-step and number of control elements was investigated. The values of the time-step to describe the variation of the measured weather data and the length of each $i^{\text {th }}$ element, selected for conducting numerical simulations, are $600 \mathrm{~s}$ and $0.05 \mathrm{~m}$, respectively. 


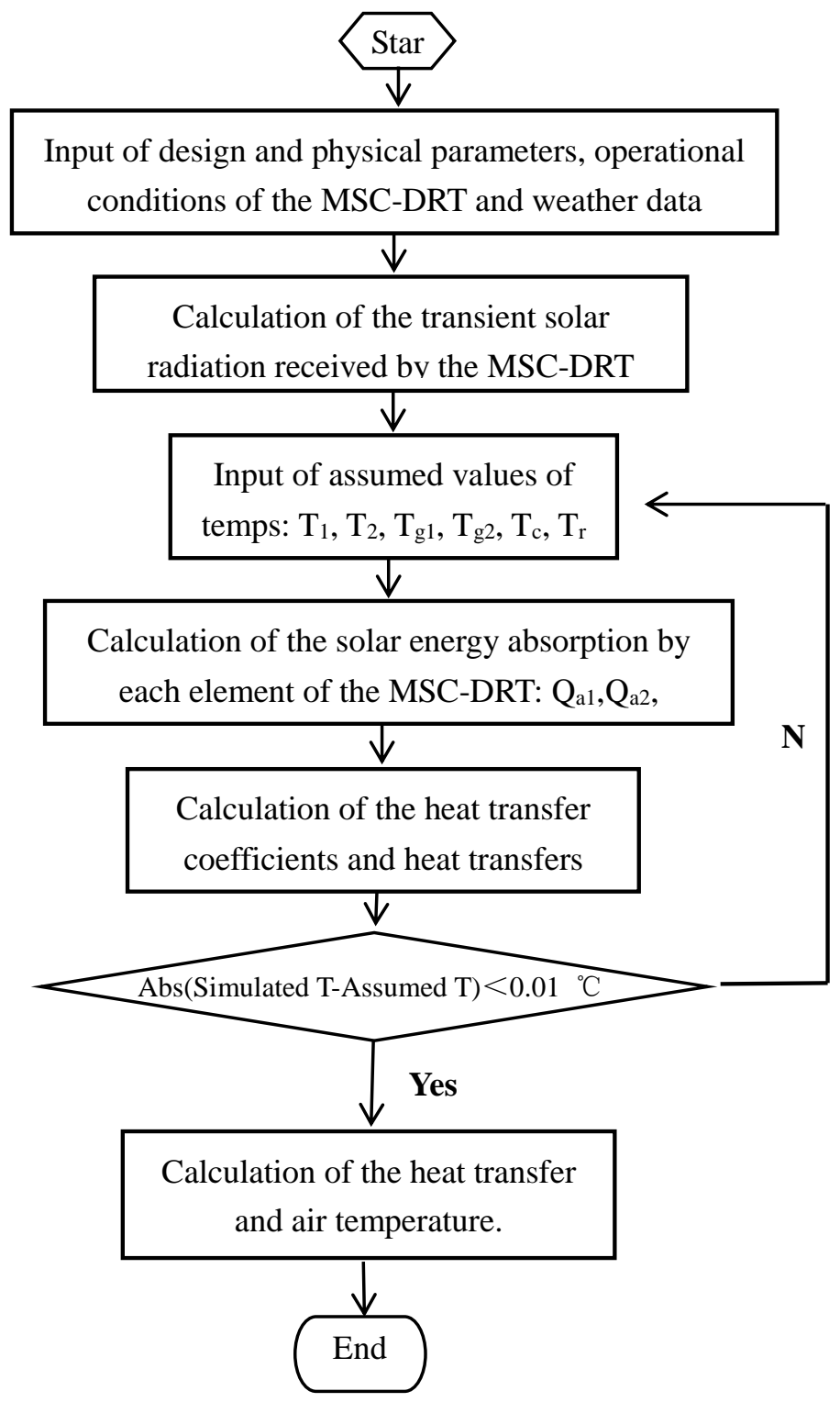

Fig. 8 The algorithm of calculations using the mathematical model of the MSC-DRT.

\section{Experimental validation of the accuracy of the MSC-DRT's mathematical model using the laboratory prototype of the collector}

The laboratory experiment setup was developed and built at Beijing University of Technology, China $\left(40.17^{\circ} \mathrm{N}, 116.39^{\circ} \mathrm{E}\right)$ to validate the accuracy of the proposed mathematical model of the MSC-DRT, see Fig. 9. The test rig consists of the 2-m MSC-DRT with PVC inlet and outlet collectors and air fan (Fig. 9a), PC-3 weather station (Fig.9b) and the temperature logger Agilent 34970A. Materials used, their optical parameters and dimensions of the MSC-DRT components are listed in Tab. 1. The experimental MSC-DRT faces the south and has a tilt angle of $45^{\circ}$. The air velocity inside each receiver glass tube was $2.1 \mathrm{~m} / \mathrm{s}$. 


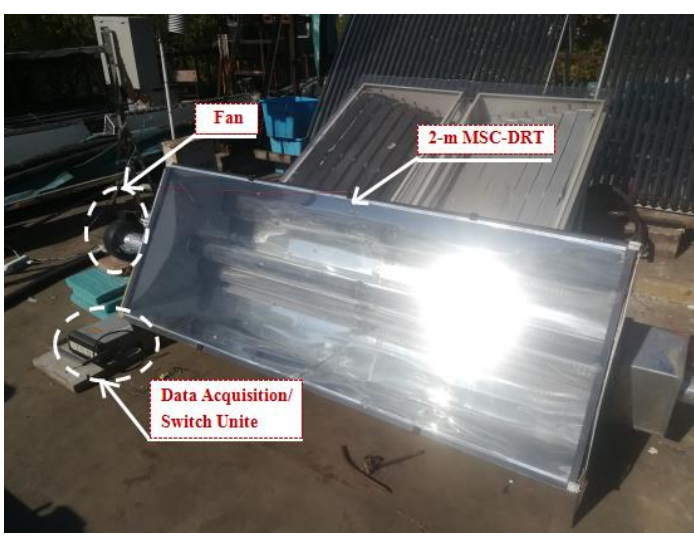

a. The 2-m MSC-DRT

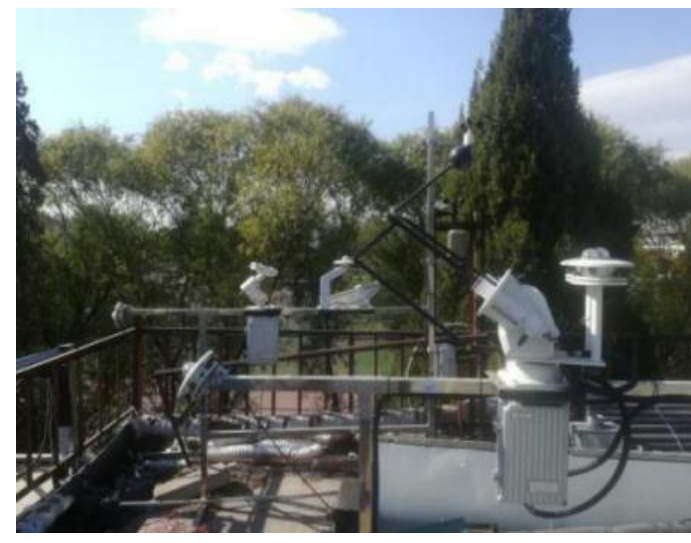

b. PC-3 weather station

Fig. 9 The experimental setup with the 2-m laboratory MSC-DRT and instrumentation.

The weather station PC-3 continuously measures irradiance, air temperature and wind speed with accuracies of $\pm 10 \mathrm{~W} / \mathrm{m}^{2}, \pm 0.4{ }^{\circ} \mathrm{C}$ and $\pm 0.3 \mathrm{~m} / \mathrm{s}$, respectively. K-type thermocouples (accuracy of $\pm 0.3{ }^{\circ} \mathrm{C}$ ) connected to the temperature data logger Agilent $34970 \mathrm{~A}$ were used to record the inlet and outlet air temperature in the MSC-DRT. A hot-wire anemometer Testo-435 was used to measure the air velocity inside the receiver tube with an accuracy of $\pm 0.01 \mathrm{~m} / \mathrm{s}$. The test rig was run from 9 am to $4 \mathrm{pm}$, which is the typical winter daytime in the Beijing Region and the frequency of sampling of experimental parameters was 10 minutes. The total radiation meter used to measure the solar radiation upon the surface of the cover glass was placed to have the same inclination angle as the MSC-DRT. The samples of measured outdoor meteorological data and the MSC-DRT inlet air temperature are shown in Fig. 10.

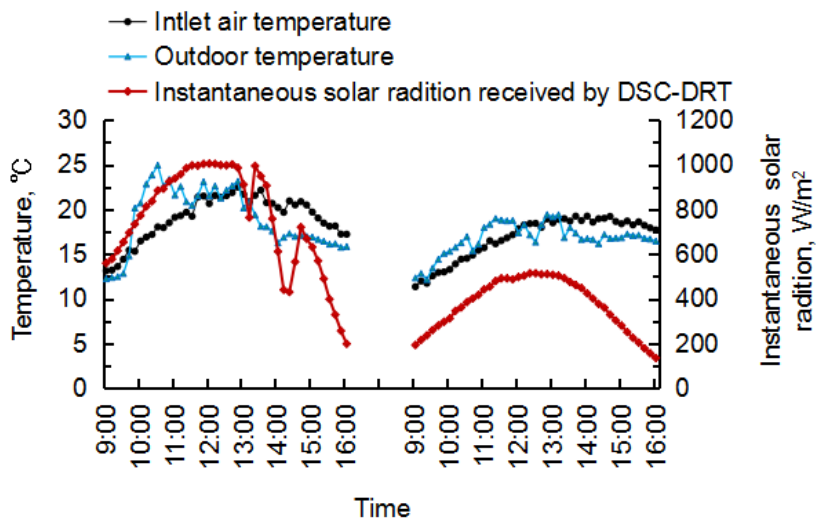

(a)

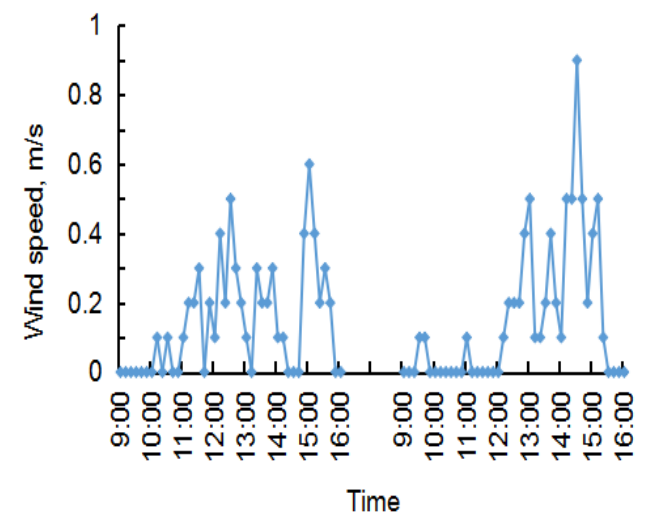

(b)

Fig. 10 Measured outdoor meteorological data (a)

and the inlet air temperature of the MSC-DCT (b) 
Measured transient data on the irradiance, outdoor wind speed, outdoor air temperature and inlet air temperature were utilized as input data in the modelling process and obtained numerical results were compared to experimental data. Fig. 11 presents the comparison between numerical and experimental results for the outlet air temperature. The quantitative values of deviation between these two sets of results are shown in Tab. 2. Both Fig. 11 and Tab. 2 demonstrate a very good agreement between theory and experiment.

In addition to the calculation of values of the maximum and average absolute and relative errors, the error analysis index IA, proposed in (Willmott, 1981), was also used in this study. The value of $I A$ is calculated as

$$
I A=1-\sum_{i=1}^{N}\left(X p_{i}-X m_{i}\right)^{2} / \sum_{i=1}^{N}\left(\left|X p_{i}^{\prime}\right|-\left|X m_{i}^{\prime}\right|^{2}\right.
$$

where

$$
\begin{gathered}
X p_{i}^{\prime}=X p_{i}-X_{\text {pave }} \\
X m_{i}^{\prime}=X m_{i}-X_{\text {mave }}
\end{gathered}
$$

The value of $I A$ varies from 0 to 1 . If $I A=1$ then the numerical value is completely consistent with the measured value. However, if $I A=0$ then the calculated value is completely inconsistent with experimental data. The calculated value of the error analysis index IA is 0.993 , which is the additional indication of the high accuracy of the mathematical model of the MSC-DRT.

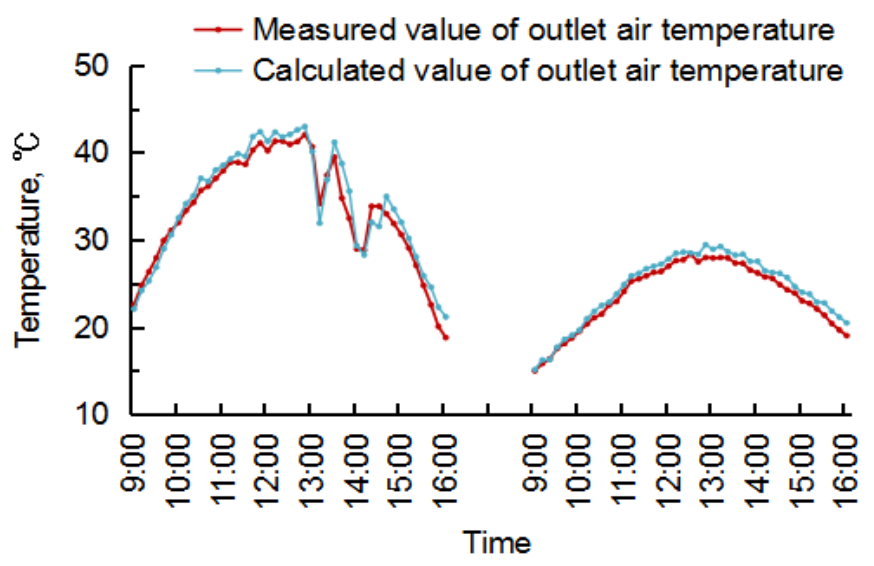

Fig. 11 Comparison of the numerical

and measured values of the outlet air temperature in the MSC-DRT. 
Tab. 2 The deviation between the numerical and measured values in the 2-m MSC-DRT

\begin{tabular}{ccccc}
\hline Index & Mean absolute & Maximum absolute & Mean relative & Maximum relative \\
& deviation, ${ }^{\circ} \mathrm{C}$ & deviation, ${ }^{\circ} \mathrm{C}$ & deviation, $\%$ & Deviation, $\%$ \\
\hline Results & \pm 1.03 & \pm 3.95 & 3.72 & 12.60 \\
\hline
\end{tabular}

In this study, a further calibration work has been carried out with regard to the efficiency of the MSC-DRT. Results on the generation of experimental and numerical efficiency curves are shown in Fig. 12. The experimental curve (standard curve) was produced by the National Solar Hot Water Quality Supervision and Inspection Center of China (Beijing) for the same version of the MSC-MDR (air-based collector). Similar results were obtained in experiments by Chen, C., Zhang, M., Zheng, H. et al., 2017. Information in Fig. 12 and the analysis presented in Tab. 3 show that the mathematical model provides accurate predictions on the thermal performance of the MSC-DRT under real experimental conditions. The obtained maximum value of the efficiency of the MSC-DRT collector at about $50 \%$ is lower than that of commercially available or some tested air-based flat plate or advanced compound parabolic collectors, and this is due to the prototype of the collector being manufactured in laboratory conditions with limited technological facilities. The later version of this collector, which was professionally manufactured at the well-equipped factory, demonstrated the efficiency of $56 \%$. The increase in the efficiency was due to ensuring the necessary precision of forms and surface quality of reflecting surfaces.

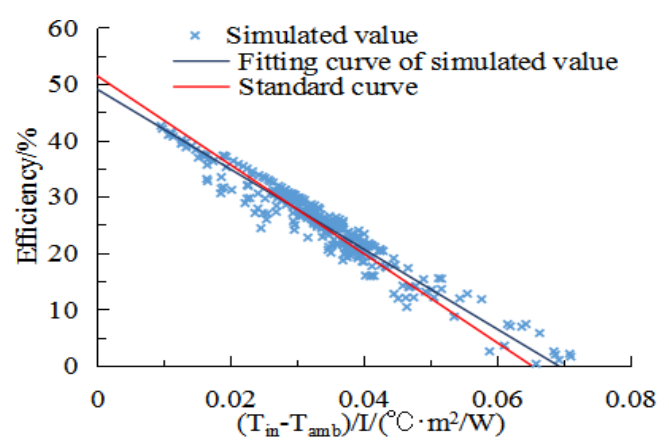

Fig. 12 Experimental and numerical efficiency curves of the MSC-DRT

(the airflow rate is $180 \mathrm{~m}^{3} / \mathrm{h}$ ). 
Tab. 3 Analysis of experimental and numerical efficiency curves of the MSC-DRT

\begin{tabular}{llccc}
\hline & Formula & $\mathrm{R}^{2}$ & $\begin{array}{c}\text { Mean relative } \\
\text { deviation, \% }\end{array}$ & $\begin{array}{c}\text { Max relative } \\
\text { deviation, \% }\end{array}$ \\
\hline Standard curve & $\eta=0.514-7.89 \times\left(T_{\text {in }}-T_{\text {amb }}\right) / I$ & - & - & - \\
Numerical curve & $\eta=0.49-7.09 \times\left(T_{\text {in }}-T_{\text {amb }}\right) / I$ & 0.91 & 4.5 & 20.36 \\
\hline
\end{tabular}

\section{Numerical analysis of the influence of meteorological and operational} parameters and design dimensions on the thermal performance of the MSC-DRT

Experimental validation of the accuracy of the developed mathematical model demonstrated its high accuracy in prediction of the performance, and it was used to numerically analyze the influence of meteorological and operational parameters and design dimensions on the thermal performance of the MSC-DRT. In numerical analysis, it was assumed that the total length of the MSC-DCTs was $4 \mathrm{~m}$ (two 2-m MSC-DRTs connected in series), air velocity inside each receiver tube was $2.1 \mathrm{~m} / \mathrm{s}$, and the air temperature in the inlet to the receiver tubes was $15^{\circ} \mathrm{C}$.

\subsection{Effect of outdoor meteorological parameters}

All the outdoor meteorological parameters vary in time, and it is very difficult to experimentally investigate the individual influence of the solar radiation, outdoor air temperature and wind speed on the thermal performance of the MSC-DRT. However, this task can be solved with the application of the calibrated mathematical model of the MSC-DRT, and Fig. 13 shows the change in the temperature rise between the inlet and outlet of the MSC-DRT and its efficiency as functions of the solar radiation intensity and outdoor air temperature for the simulated outdoor wind speed of $2 \mathrm{~m} / \mathrm{s}$. It can be seen in Fig. 13a that the temperature difference at the inlet and outlet of the MSC-DRTs increases almost linearly with the increase in solar radiation and decreases with the reduction in the outdoor air temperature. The effect of the $10{ }^{\circ} \mathrm{C}$ reduction in the outdoor air temperature is equivalent to that of the $100 \mathrm{~W} / \mathrm{m}^{2}$ reduction in the solar radiation at the same level of the outdoor air temperature. It is shown in Fig. 13b that the efficiency of the 
MSC-DRTs first increases and then gradually stabilizes with the increase in solar radiation. This effect is amplified by the rise in the level of the outdoor air temperature. The efficiency of the MSC-DRT increases with the increase in the outdoor air temperature at the same level of solar radiation.

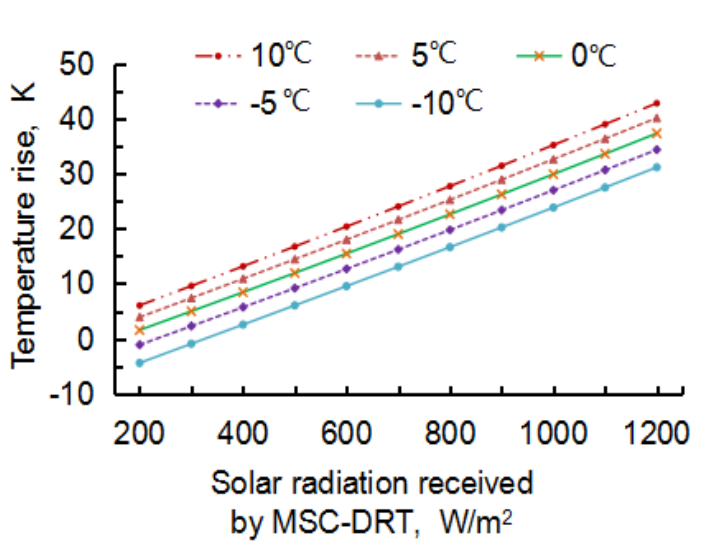

(a) Variation of temperature rise between the inlet and outlet as a function of the solar radiation and outdoor air temperature

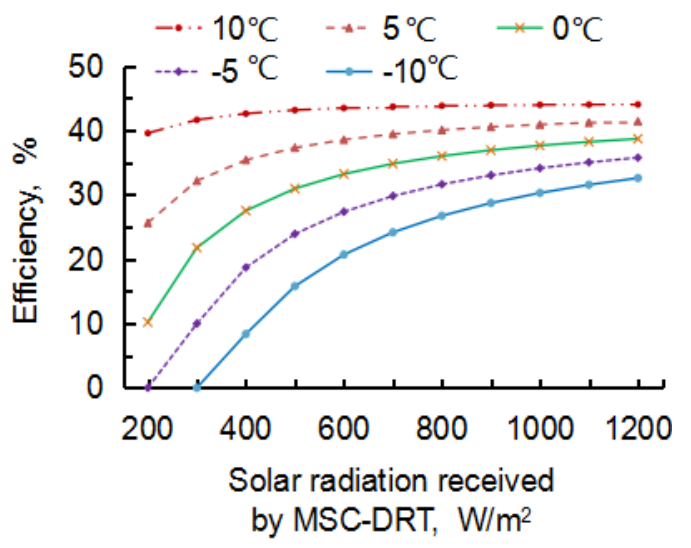

(b) Variation of the MSC-DRT efficiency as a

function of the solar radiation and outdoor air temperature

Fig. 13 Effects of the solar radiation intensity and outdoor air temperature on the thermal performance of MSC-DRT.

Fig. 14 demonstrates the simulated variation of the efficiency of the MSC-DRT as a function of the outdoor wind speed and solar radiation for the simulated outdoor temperature of $0{ }^{\circ} \mathrm{C}$ (Fig. 14a) and wind speed and outdoor air temperature for the simulated solar radiation of $800 \mathrm{~W} / \mathrm{m}^{2}$ (Fig. 14b). It can be seen in Fig. 14a that for the constant value of the outdoor air temperature, the efficiency of the MSC-DRT is unaffected by the change in the outdoor wind speed and only increases with the enhancement in solar radiation. It is shown in Fig. 14b that at the constant solar radiation value, the efficiency of the MSC-DRT slightly decreases with the increase in the outdoor wind speed. But this trend is amplified with a decrease in the outdoor air temperature. Analysis of results in Figs. 13 and 14 demonstrate that the influences of solar radiation intensity and outdoor air temperature on the thermal performance of the MSC-DRT are significantly greater than that of the outdoor wind speed. The influence of the outdoor wind speed on the thermal performance of the MSC-DRT can be neglected if the outdoor temperature is higher than $-5^{\circ} \mathrm{C}$. 


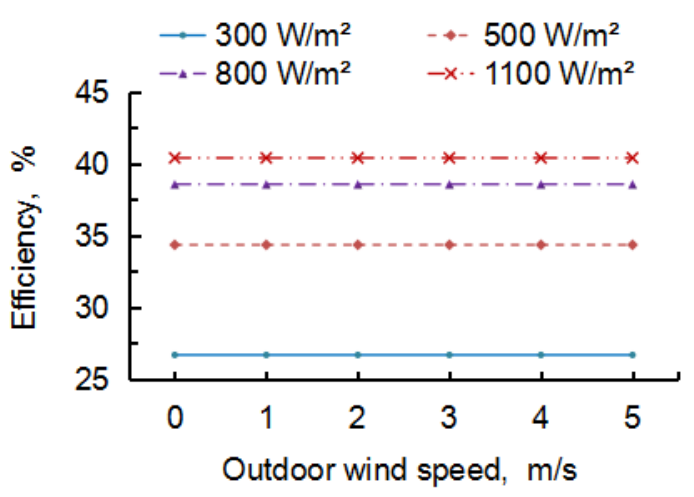

(a) Variation of the efficiency as a function of the wind speed and solar radiation (the outdoor temperature is $0^{\circ} \mathrm{C}$ )

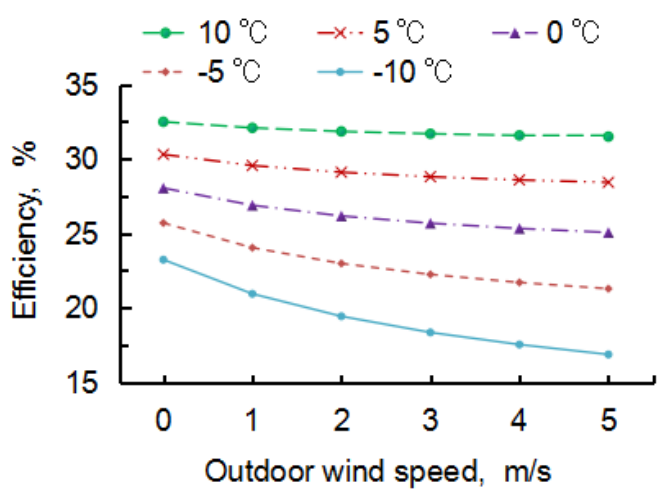

(b) Variation of the efficiency as a function of the wind speed and outdoor air temperature (the solar radiation is $800 \mathrm{~W} / \mathrm{m}^{2}$ )

Fig. 14 Effects of the outdoor wind speed, solar radiation and wind speed on the efficiency of the MSC-DRT.

\subsection{Effect of the air velocity inside the receiver tubes}

The value of the air velocity in the receiver tubes of the MSC-DRT should be carefully selected for the given values of the outdoor meteorological parameters and inlet air temperature in order to achieve the maximum heat gains in the winter period when the MSC-DRT is integrated with passive-active ventilation wall of the greenhouse.

The daily operation of the solar greenhouses in the Beijing Region can be divided into the following three stages, according to the operational conditions:

Stage 1 - From 8:00 a.m to 10:30 a.m. The outdoor temperature is low and varies between -6 and $0{ }^{\circ} \mathrm{C}$, the solar radiation gradually increases from 300 to $600 \mathrm{~W} / \mathrm{m}^{2}$, and the inlet air temperature is relatively low and varies between 12 and $20^{\circ} \mathrm{C}$.

Stage 2 - From 10:30 a.m to 14:30 p.m. The above three parameters reach their highest values, and the outdoor air temperature is between 2 and $8{ }^{\circ} \mathrm{C}$, the solar radiation is between 700 and $1000 \mathrm{~W} / \mathrm{m}^{2}$ and the inlet air temperature is between 22 and $30^{\circ} \mathrm{C}$.

Stage 3 - From 14:30 p.m. to 16:00 p.m. The values of the above three parameters are gradually decreasing, and the outdoor air temperature is between 0 and $6{ }^{\circ} \mathrm{C}$, the solar radiation is between 300 and $600 \mathrm{~W} / \mathrm{m}^{2}$ and the inlet air temperature is between 18 and $24{ }^{\circ} \mathrm{C}$.

Considering that the outdoor temperature varies insignificantly within each stage, this value 
was set to $-2,4$ and $2{ }^{\circ} \mathrm{C}$ for respective stages and the mathematical model of the MSC-DRT was used to numerically simulate the influence of the air velocity inside the receiver tubes on the thermal performance of the 4-m design of the collector at the different values of the solar radiation. The obtained numerical results are shown in Figs. 15-17. It can be seen that at the same solar radiation, the temperature rise between the inlet and outlet of the MSC-DRT decreases gradually with the increase of the air velocity in the receiver tube at all stages of operation. This effect is decreased with a decrease in the solar radiation.
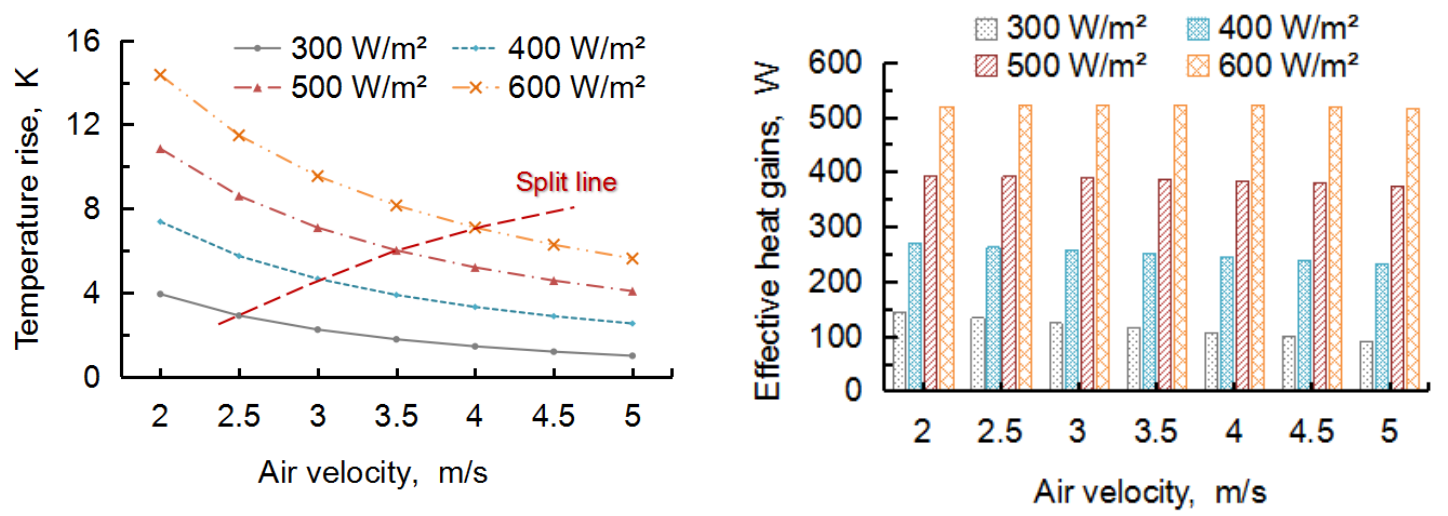

Fig. 15. Variation of the air temperature rise and effective heat gain as a function of the air velocity in the receiver tube (Stage 1)
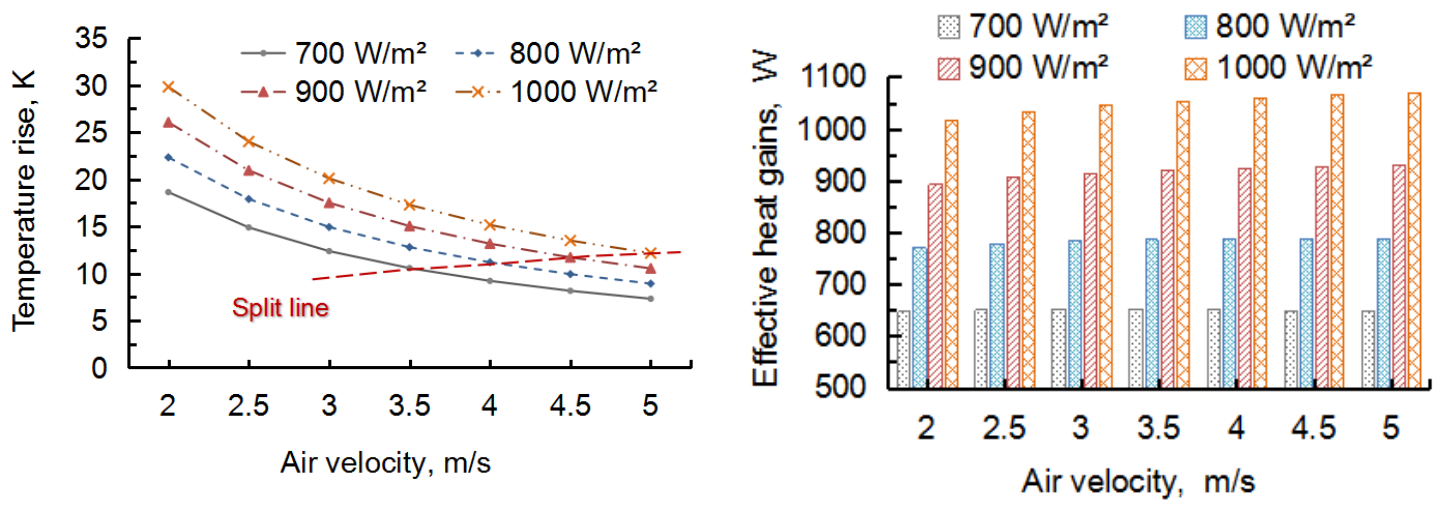

Fig. 16. Variation of the air temperature rise and effective heat gain as a function of the air velocity in the receiver tube (Stage 2) 

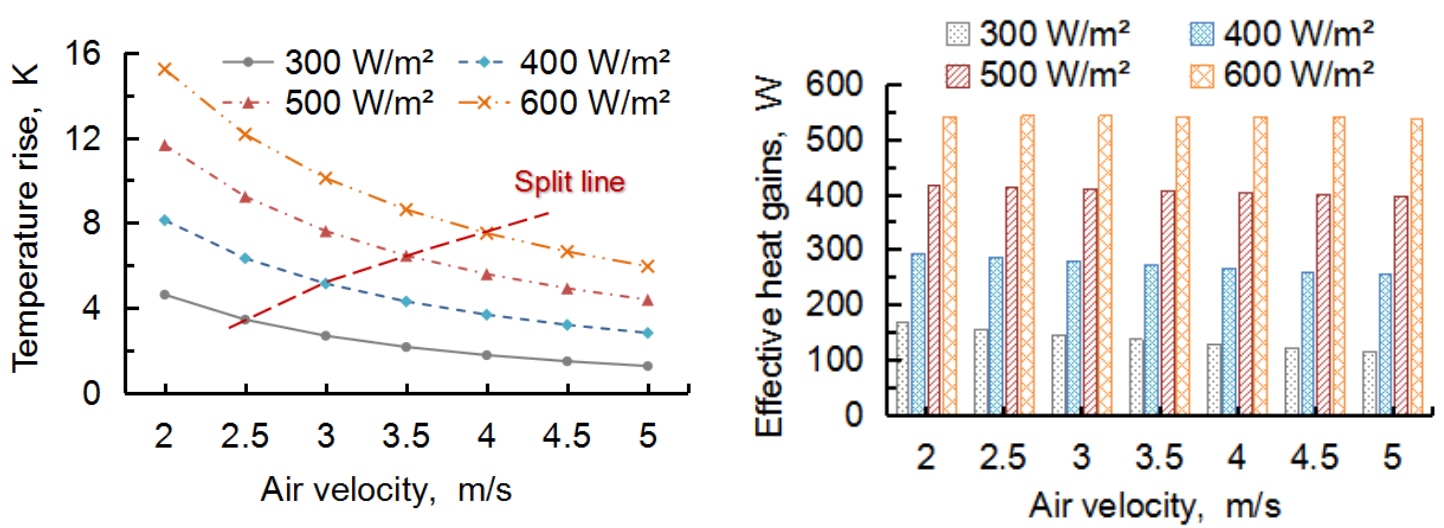

Fig. 17. Variation of the air temperature rise and effective heat gain as a function of the air velocity in the receiver tube (Stage 3)

Fig. 15 (Stage 1) and Fig. 17 (Stage 3) demonstrate that for the solar radiation and outdoor air temperature being relatively low, the effective heat gain decreases with the increase of the air velocity in the receiver tube, while the air temperature first decreases, and then stabilizes despite the rise in the air velocity in the receiver tube. The air velocity in the receiver tube should be no higher than the values limited by the split lines. The rise of air velocity higher than that indicated by the split lines will result in the simultaneous reduction of both the heat gain and outlet air temperature in the MSC-DRT, integrated with the active-passive ventilation wall with the latent heat storage.

Fig. 16 (Stage 2) demonstrates that for the conditions, in which the outdoor air temperature, solar radiation and the air inlet temperature are high at the noon, the temperature rise and the effective heat gain in the MSC-DRT increases with the increase of the air velocity in the receiver tube. The use of the velocity values lower than that indicated by the split line results in the reduction of the heat gain. Therefore during this second stage of operation, the air velocity in the receiver tube should be set higher than the values limited by the split line in Fig. 16 in order to achieve greater values of the effective heat gain in the MSC-DRT, which then will be delivered to the active-passive ventilation wall with the latent heat storage.

\subsection{Effect of the collector's length}

In practical applications, the length of the MSC-DRT should be selected so the outlet air temperature and the effective heat gain are maximized. In the numerical simulation process, the actual outdoor meteorological parameters, typical for a sunny day (as presented in Fig. 10) and the 
inlet air temperature of $20^{\circ} \mathrm{C}$ were used to investigate the influence of the length of the MSC-DRT on its thermal performance at different air velocities in the receiver tube. The obtained numerical results are presented in Figs. 18 and 19.
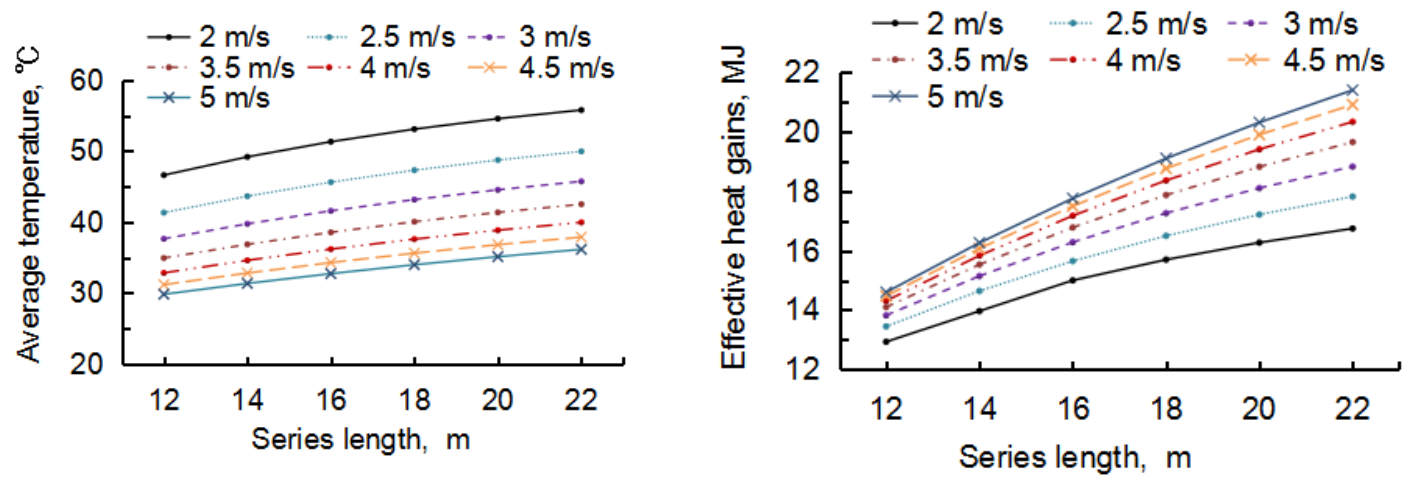

Fig. 18. Variation of the average outlet air temperature and effective heat gain as a function

of the MSC-DRT length (Stages 1 and 3).
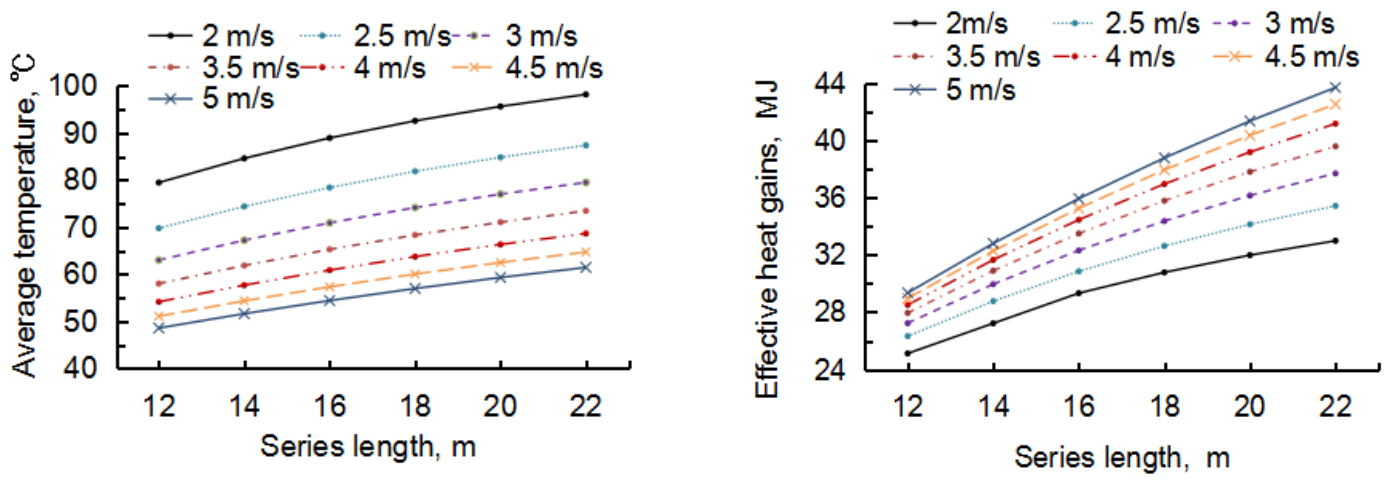

Fig. 19. Variation of the average outlet air temperature and effective heat gain as a function of the MSC-DRT length (Stage 2).

It can be seen that at the same air velocity in the receiver tube, the average outlet air temperature and effective heat gain rise with the increase in the length of the MSC-DRT, but the rate of rising decreases with the increase in the length of the collector. This trend is more evident at the low air velocity in the receiver tube. The growth in the effective heat gain slows down significantly if the length of the collector is longer than $18 \mathrm{~m}$. Therefore, at the sufficient level of the outlet air temperature, the length of the MSC-DRT should not be longer than $14 \mathrm{~m}$. 


\section{Experimental results from testing the full-scale MSC-DRT integrated into the greenhouse with passive-active ventilation wall and latent thermal storage}

In order to experimentally measure benefits, the full-scale MSC-DRT into the experimental solar greenhouse with the active-passive ventilation wall and latent heat storage was built in Beijing Region. Figs. 20 and 21 present the schematic and physical appearance of such the system. The dimensions of the experimental greenhouse are as follows: the length is $40 \mathrm{~m}$ from east to west, and the width is $10 \mathrm{~m}$ from north to south. The orientation of the greenhouse is $6^{\circ}$ south to the west. The north wall height is $3.5 \mathrm{~m}$, the ridge is $4.8 \mathrm{~m}$, and the horizontal projection length of the rear roof is $1.2 \mathrm{~m}$. The east and west walls are made of bricks and are $0.48 \mathrm{~m}$ thick. The back roof is equipped with an100-mm thick polyphenyl insulation material. The front roof is made of 0.12-mm thick EVA film spread over stainless steel frames and during nighttime is covered with a 40-mm thick insulation quilt.

The design of the north wall is briefly described in Fig. 5, and it is part of the active-passive ventilation system. The interior surface of the wall is covered by a $40-\mathrm{mm}$ thick GH-20 composite phase change material wallboard, and the interior of the wall is $390-\mathrm{mm}$ thick and made of concrete blocks and bricks. It has several vertical air passages. A 100-mm thick polyphenyl insulation board covers the exterior surface of the wall. The GH-20 composite phase change material was developed internally at the Beijing University of Technology, and it has the melting temperature equal to $20^{\circ} \mathrm{C}$.

The developed mathematical model of the MSC-DRT was used to determine the length of the collector and for the calculated heating demand of this solar greenhouse. As a result of simulations, two active-passive heat storage ventilation systems with 16-m MSC-DRTs were used in the building. 


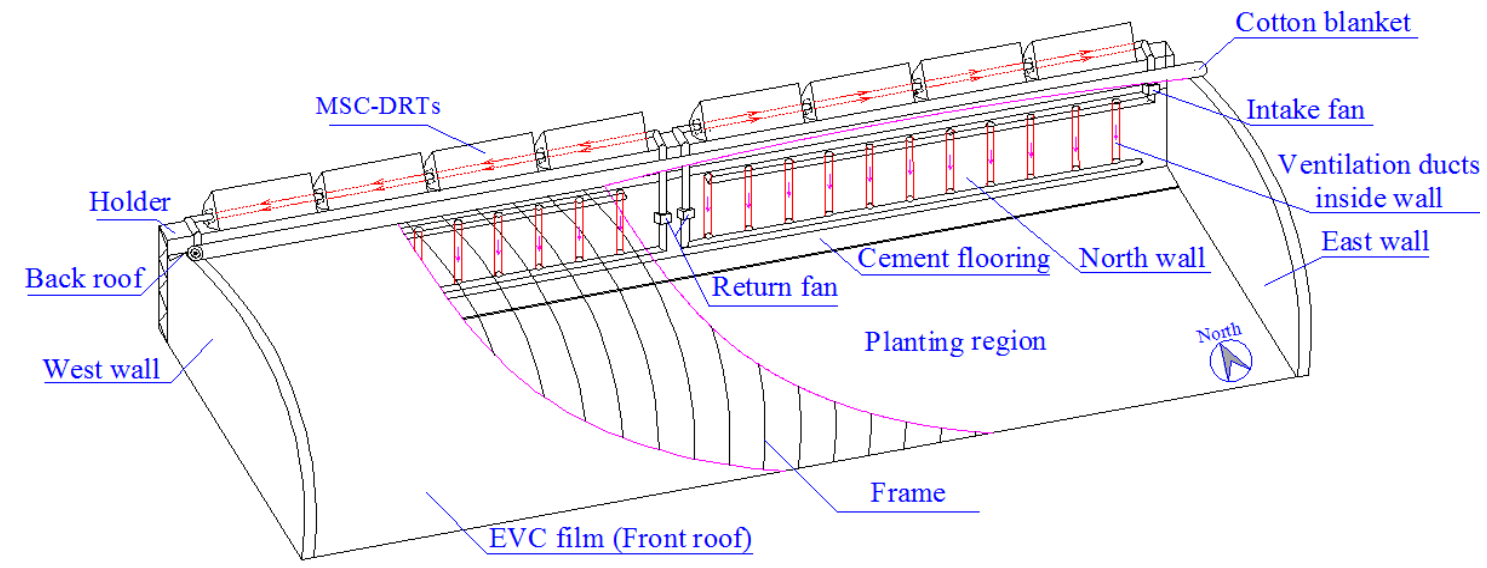

Fig. 20 Schematic of the experimental solar greenhouse with the MSC-DRTs.
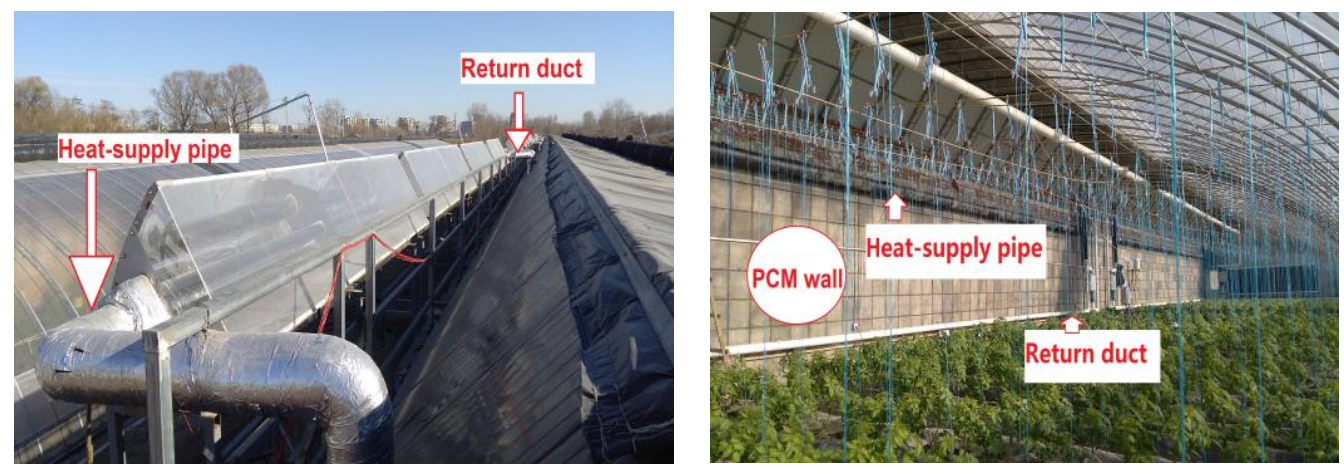

Fig. 21 The appearance of the installed MSC-DRTs and interior

of the experimental solar greenhouse.

To maximize the active heat gain by the MSC-DRT during the winter period (from 28 November to 28 February), the solar altitude angles at 9:00 am on 23 December and at 12:00 noon on 28 February were selected as the low and upper values of the solar altitude angle range, as shown in Fig. 22. This range of the solar altitude angle ensures the $\pm 20^{\circ}$ range of solar radiance incidence angle required for the requested level of the MSC-DRT (in accordance with the LightTools software simulation results). Fig. 22 shows that the average values of the upper and the lower ends of the range of the solar altitude angle are determined by the installation angle of the MSC-DCT. Therefore, the installation angle $\beta$ (the angle between the central axis of the collector and the horizontal plane) of the MSC-DRT was selected to be $24^{\circ}$. 


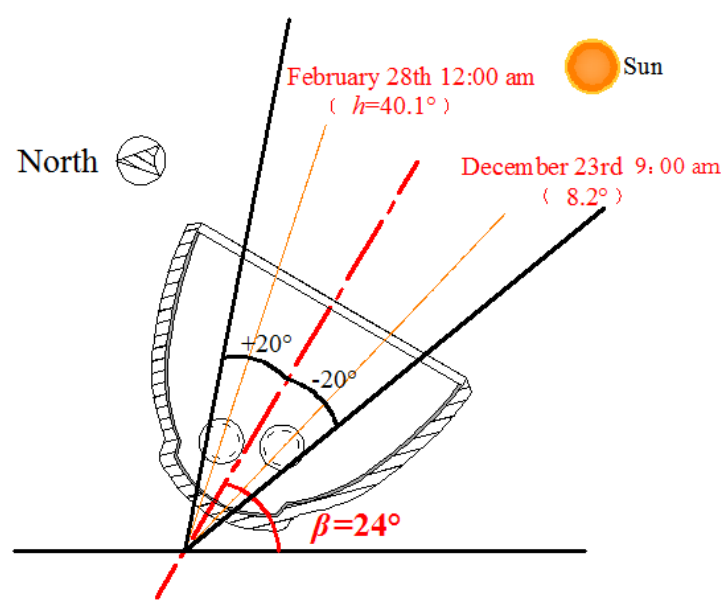

Fig. 22 Selection of the installation angle for the MSC-DRT in the Beijing Region.

Continuous monitoring and recording of relevant experimental parameters was performed during experiments in winter months in the full-scale solar greenhouse, shown in Fig. 21, to determine the effect of the installed novel MSC-DRT. This greenhouse system was run daily from $8: 30$ to $16: 30$. The air velocity inside the single receiver tube was set to $4 \mathrm{~m} / \mathrm{s}$.

The instrumentation used is similar to that deployed in the tests of the laboratory prototype. The PC-3 weather station continuously measured and recorded the outdoor meteorological parameters, namely the solar radiation, outdoor air temperature and wind speed with accuracies of $\pm 10 \mathrm{~W} / \mathrm{m}^{2}, \pm 0.4{ }^{\circ} \mathrm{C}$ and $\pm 0.3 \mathrm{~m} / \mathrm{s}$ respectively. K-type thermocouples with an accuracy of $\pm 0.3{ }^{\circ} \mathrm{C}$ and connected to the temperature data logger were used to record the inlet and outlet air temperatures in the MSC-DRTs, indoor air temperature, indoor soil temperature and inner surface temperature of the north wall in several locations. Fig. 23 shows location of thermocouples in the greenhouse. A hot-wire anemometer Testo-435 with an accuracy of $\pm 0.01 \mathrm{~m} / \mathrm{s}$ was used to measure the air velocity inside the receiver tube. Fig. 24 shows, as an example, the measured outdoor meteorological parameters and the inlet air temperature on 20 January 2019. 


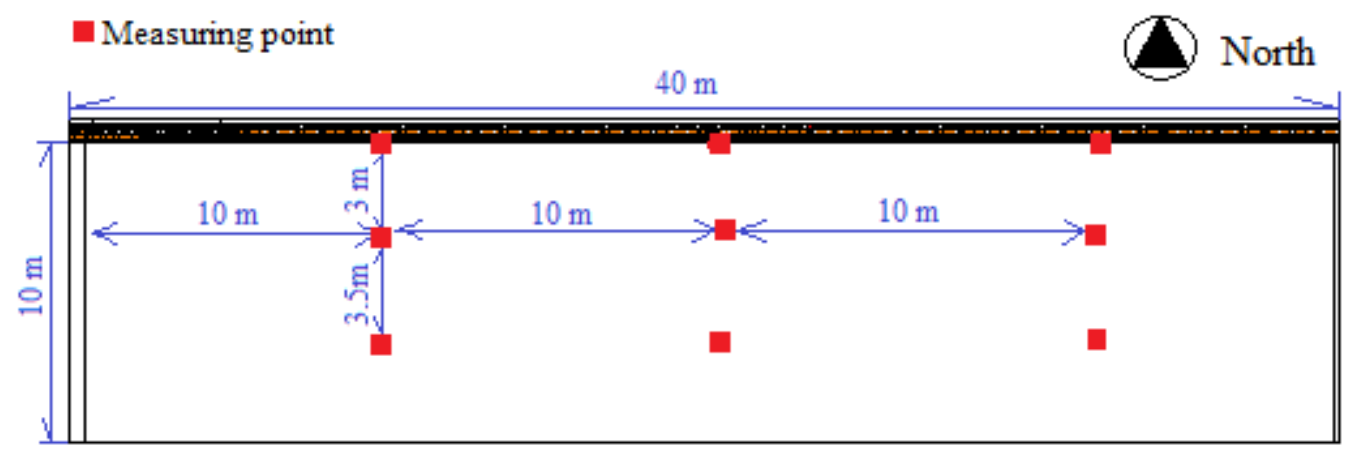

(a) the view from the top

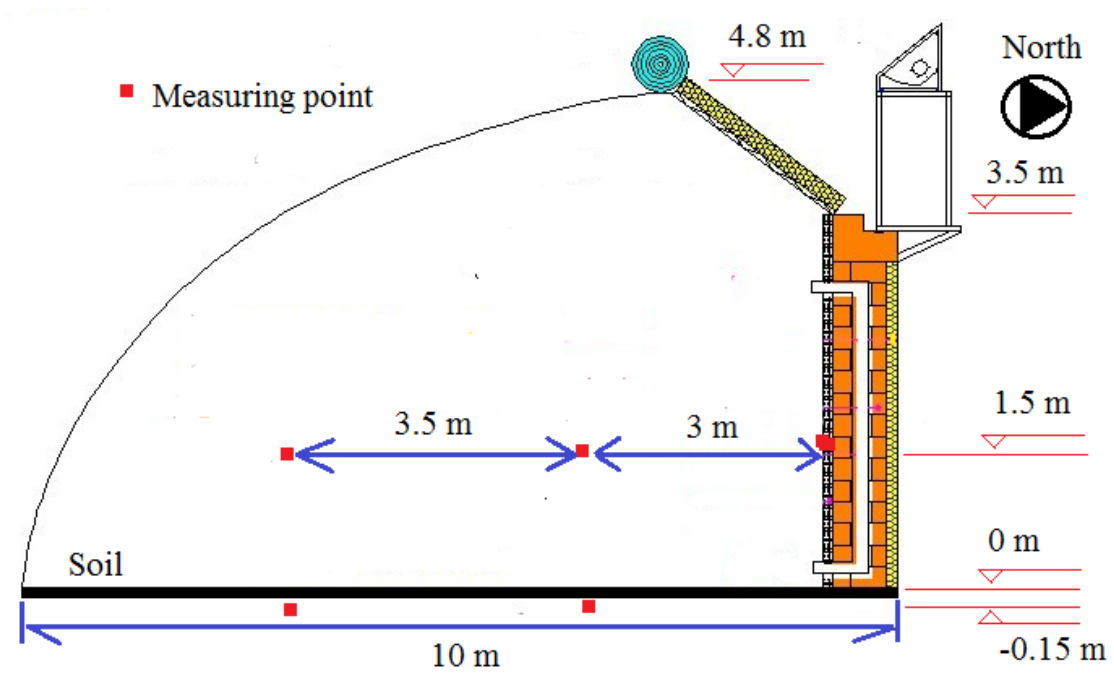

(b) the side view

Fig. 23 Location of thermocouples in the greenhouse
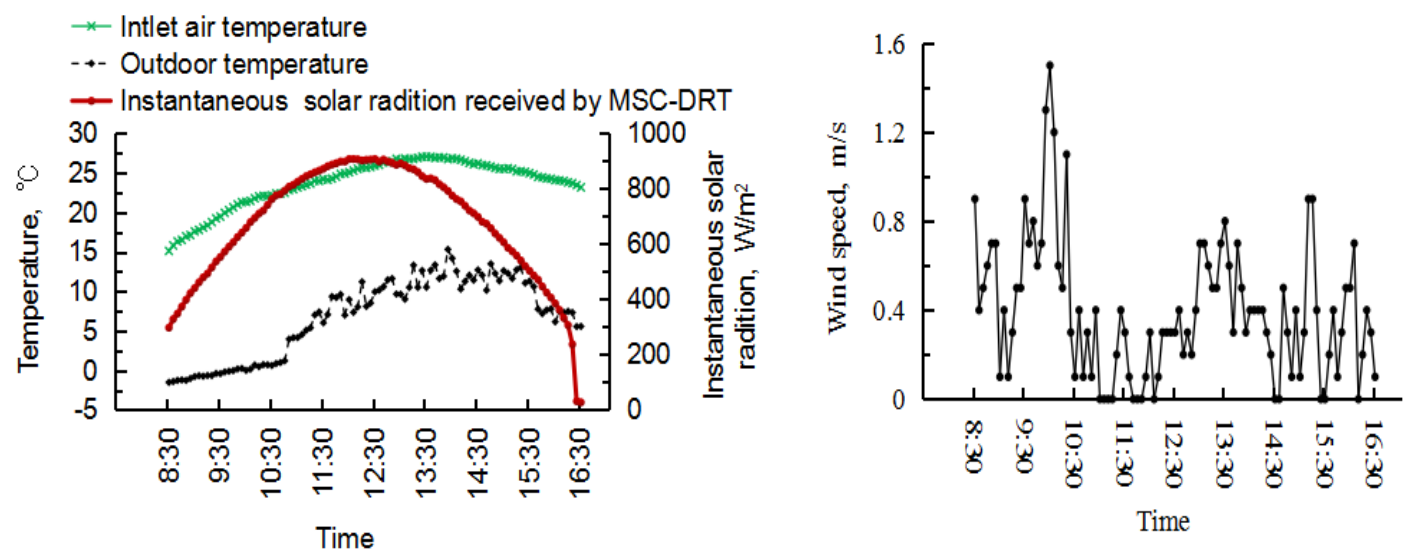

Fig. 24 Outdoor meteorological conditions and the inlet air temperature in the 16-m MSC-DRTs on 20 January 2019 (sunny conditions).

Fig. 25 shows the comparison of some indoor temperatures experimentally recorded in the 
experimental greenhouse with the MSC-DRTs and identical conventional greenhouse. This data was obtained during the period between 19 and 23 January 2019 .

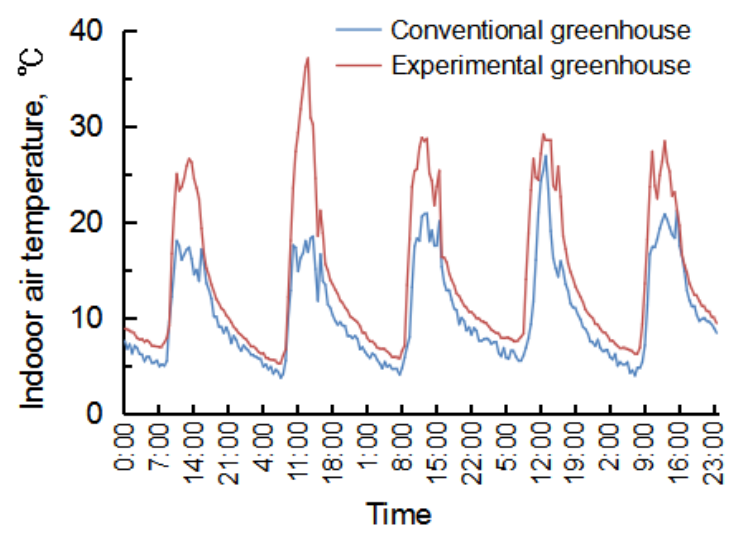

(a) Variation of the indoor air temperature with time

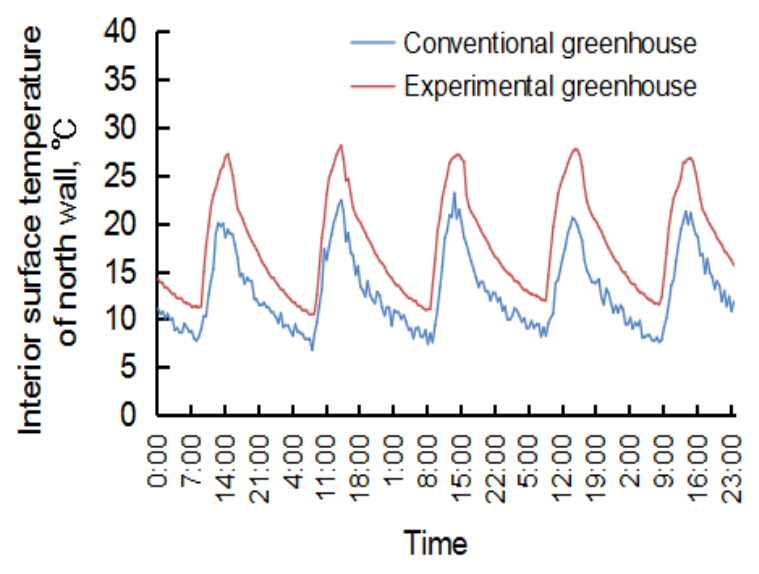

(b) Variation of the north wall interior surface with time

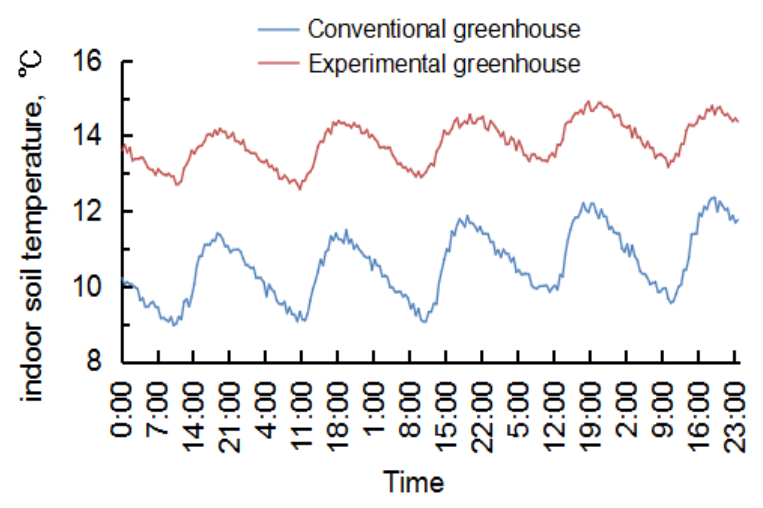

(c) Variation of the indoor soil temperature with time

Fig. 25 Comparison of recorded temperatures in the experimental greenhouse with MSC-DRTs and conventional greenhouse. 
The experimental results demonstrate that at nighttime, the active-passive heat storage ventilation system with MSC-DRTs increases the average (averaged across the greenhouse) temperatures of the north wall inner surface by $7.5^{\circ} \mathrm{C}$, indoor air by $1.8^{\circ} \mathrm{C}$ and indoor soil by $1.5^{\circ} \mathrm{C}$.

\section{The combined use of the mathematical model of the MSC-DRT and EnergyPlus model of the experimental greenhouse for estimation of energy savings}

The mathematical model of the MSC-DRT was coupled with EnergyPlus software modelling of the greenhouse with passive-active ventilation wall and latent thermal storage. Building energy analysis software EnergyPlus was used to calculate the daily heat load of the solar greenhouse of the same size and the high accuracy of such modelling was demonstrated in (Chao et al., 2019). The purpose of the combined modelling in this work is to determine the rational inlet air velocity profile variation during the daytime in the December-January period to achieve a close match between heat demand of the greenhouse and heat gain by the solar collector and to improve fuel and $\mathrm{CO}_{2}$ savings.

Fig. 26a demonstrates results for daytime and there is a very close agreement between the measured and numerically modelled outlet air-temperature for weather conditions in the December-January period for the air-velocity in the receiver tube of $4 \mathrm{~m} / \mathrm{s}$. The temperature varies from about 25 to $80^{\circ} \mathrm{C}$. The acceptable range of the outlet air temperature for the greenhouse requirements is between 40 and $70{ }^{\circ} \mathrm{C}$ (Ling Haoshu, 2017). The average and the maximum errors are $3.1 \%$ and $8.6 \%$ between the measured and predicted values of the outlet air temperature. Figure $26 \mathrm{~b}$ presents information on the values of the heat gain and collector's efficiency for the air velocity in the receiver tube of $4 \mathrm{~m} / \mathrm{s}$. The heat gain varies from about $600 \mathrm{~J}$ in the morning time to $4000 \mathrm{~J}$ at noon. The maximum value of the collector's efficiency is about $40 \%$. Fig. 25a shows results on the calculation of heat demand in the experimental greenhouse and heat gains by the full-scale experimental MSC-DRT for the December-January period.

Fig. 26a shows the rationalized profile of the air velocity in the receiver tube, which is increased to $6 \mathrm{~m} / \mathrm{s}$ in steps depending on the time during the day. The increased velocity reduces the air outlet temperature to $70{ }^{\circ} \mathrm{C}$ but increases the maximum heat gain and collector's efficiency values to about $4500 \mathrm{~J}$ and $48 \%$. 


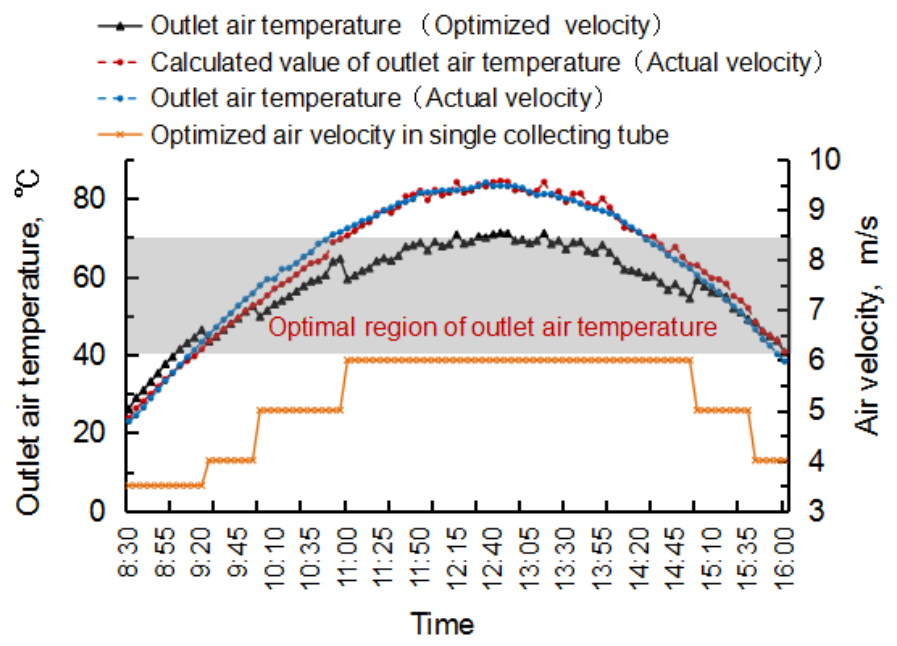

(a) The actual outlet air temperature of MSC-DRTs and its rationalization by model

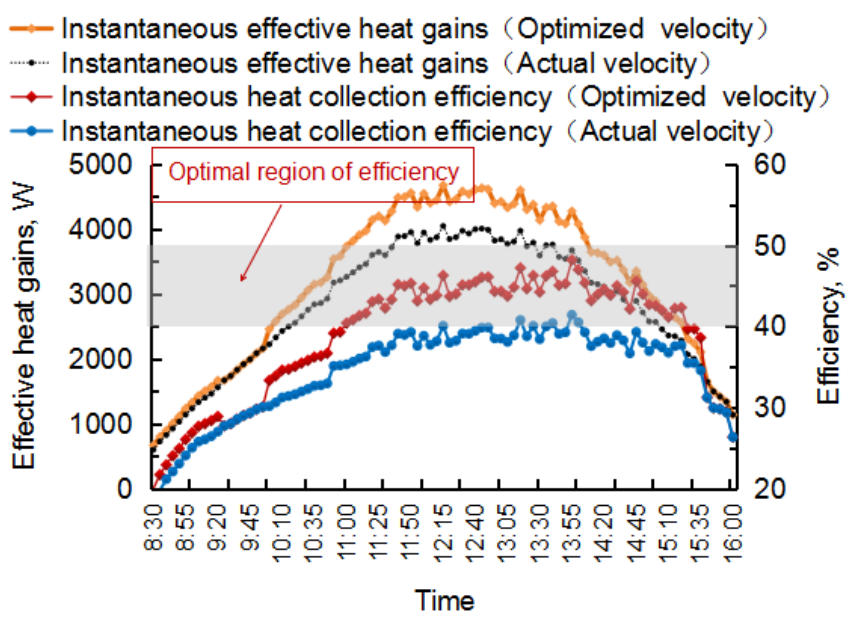

(b) Actual effective heat gains and efficiency of MSC-DRTs, and their rationalization by model

Fig. 26 The actual thermal performance of MSC-DRTs and its numerical rationalization.

The outlet air temperature of the collector should be maintained at a particular range. The minimum temperature is defined by the necessity to provide the required level of the heat transfer between hot air and the surface of air channels inside the wall. The upper limit of the air temperature is achieved at minimum allowable airflow, further reduction of which would reduce the storage in the wall of the active heat gains. In the experimental work by Ling Haoshu (2017) it was determined that the outlet air temperature of the collector should be between 40 and $70{ }^{\circ} \mathrm{C}$. It is shown in Fig. 26 that the outlet air temperature for rationalized inlet air velocity is in the above-recommended range.

As shown in Fig. 26a, MSC-DRT mathematical heat transfer model was used to rationalize 
the inlet air velocity to make MSC-DRTs have more active heat gains, higher efficiency, and appropriate air outlet temperature. It is shown in Fig. 26 that, compared with the actual condition, the outlet air temperature under the condition of rationalized inlet air velocity can meet the requirements at most times of this day. Daily effective heat gains and daily average efficiency of MSC-DCTs are increased by $12.94 \%$, and the efficiency achieved is between 40 and $50 \%$ at noon and afternoon periods. Currently, experimental data on the dependence of the optical efficiency on the solar altitude and azimuth angles is being accumulated to validate corresponding theoretical results.

Fig. 27 shows the daily heat load of the solar greenhouse and the daily effective heat gains in the December- January period. It can be seen in Fig. 27a, that the MSC-DRTs integrated into the experimental solar greenhouse in the Beijing Region provides $11830.8 \mathrm{MJ}$ of active heat gains during these two winter months. During these two months, the MSC-DRTs could not be operated for five days due to the low outdoor solar radiation. The MSC-DRTs can provide between $11 \%$ and $81 \%$ of the heat load, depending on weather conditions, and save $404 \mathrm{~kg}$ of coal during the above period.

As shown in Fig. 27b, the MSC-DCTs provide a greater heat gain of $2676.9 \mathrm{MJ}$ after the rationalized variable air velocity profile is implemented in the receiver tube. This is $12-37.9 \%$ higher (with the average increase of $18 \%$ ) than that with $4 \mathrm{~m} / \mathrm{s}$ air velocity. Also, the daily average collector efficiency is increased to $36 \%$. Following the same approach and using statistical meteorological data, it is possible to rationalize the variation of the air velocity in the receiver tubes over the longer periods. 


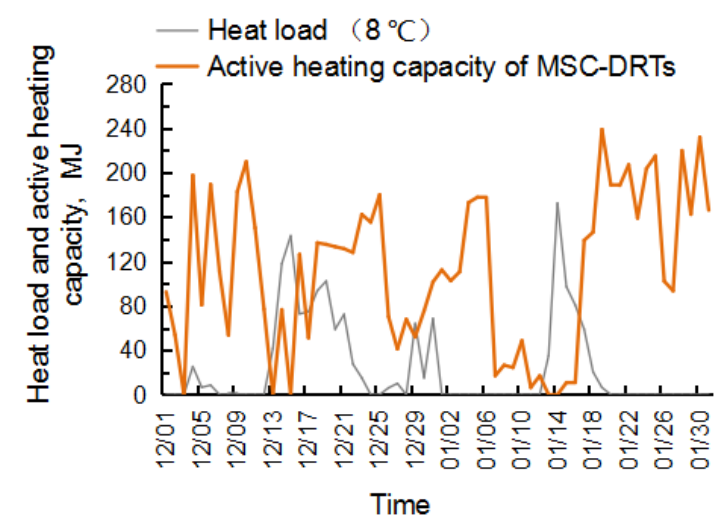

(a) The daily heat load of the solar greenhouse and the daily heat gain by the MSC-DRT with the air velocity of $4 \mathrm{~m} / \mathrm{s}$

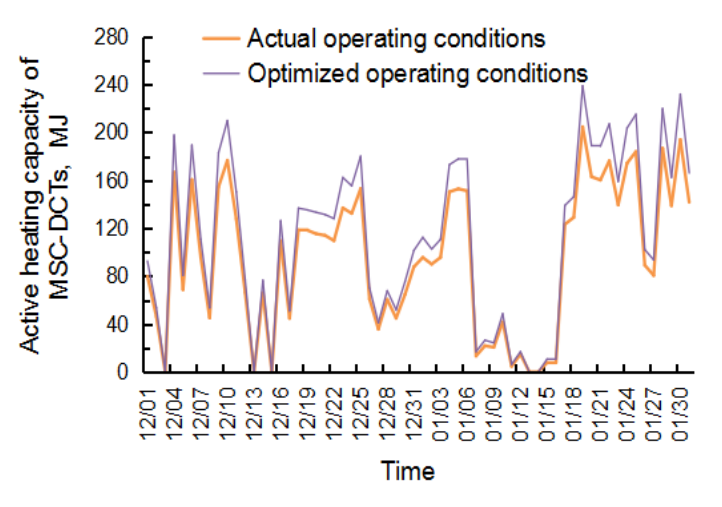

(b) Heat gains of the MSC-DRT with constant (4 $\mathrm{m} / \mathrm{s}$ ) and rationalized variable air velocities

Fig. 27 The daily heat load of the solar greenhouse and the daily heat gain of the MSC-DRT in the December-January period.

\section{Conclusions}

- The design of a novel multi-surface solar air collector with double-receiver tubes (MSC-DRT) was developed using LighTools optical modelling software. The proposed design was tested in laboratory conditions using a laboratory prototype and by deploying the full-scale prototype, integrated into the solar greenhouse with active-passive ventilation wall and latent thermal storage.

- For solar radiation incidence angles (on the glass cover of the MSC-DRT) in the range from $0^{\circ}$ to $\pm 20^{\circ}$, the total sunbeams convergence coefficient of the MSC-DRT is between 0.74 and 1 with the average value of 0.90 without a sun-tracking device.

- The lumped-parameter mathematical model of the MSC-DRT was developed which was validated using test results from laboratory and full-scale prototypes. The comparison of numerical and experimental results demonstrated the capacity of the developed mathematical model to predict the thermal performance of the MSC-DRT with a very high accuracy.

- Using this model, the influences of outdoor meteorological parameters, air velocity in the receiver tube, and of its length on the thermal performance of MSC-DRT were analyzed. The air velocity variation in the receiver tube during daytime was rationalized to achieve the highest heat gains by the MSC-DRT, installed on the solar greenhouse. 
- Experiments show that the MSC-DRT provides a heat gain of 11830.8 MJ in the December-January period and satisfies $11-81 \%$ of the heat load of greenhouse in the unfavourable weather conditions in the Beijing Region. The MSC-DRT with the rationalized profile of the air velocity in the receiver tubes improves the heat gain by $12-37.9 \%$ and increases the daily average collector efficiency up to $36 \%$.

- Compared to the conventional greenhouse, the use of the greenhouse with active-passive ventilation wall and latent heat storage, equipped with the MSC-DRTs increases the average values of the inner surface temperature of the north wall, indoor air temperature at night and indoor soil temperature by $7.5^{\circ} \mathrm{C}, 1.8^{\circ} \mathrm{C}$ and $1.5^{\circ} \mathrm{C}$, respectively.

- The results of this study demonstrate that the proposed novel design of the MSC-DRT has a certain technical and economic advantages over existing technologies, including flat-plate, evacuated tube or parabolic trough air collectors, and is a feasible technical solution for further reduction of $\mathrm{CO}_{2}$ emissions and consumption of fossil fuels in heating of greenhouses in regions with the high solar radiation and cold winters.

\section{Acknowledgement}

This work was partially supported by Key R \& D projects of Ningxia Hui Autonomous Region (2019BFF02005); The National Natural Science Foundation of China (51578012, 51368060); National Key R \& D Program of the "13th Five Year Plan" Period (2016YFC0700206).

\section{References}

A. Acuna, N. Velázquez, D. Sauceda et al., 2017. Modeling, construction, and experimentation of a compound parabolic concentrator with a concentric tube as the absorber. J. Energy Eng. 143(3), 04016059.

Attar, I., Farhat, A., 2015. Efficiency evaluation of a solar water heating system applied to the greenhouse climate. Solar Energy. 119, 212-224

Bao, E., Cao, Y., Zou, Z. et al., 2018. Research progress of thermal storage technology in energy-saving solar greenhouse. Transactions of the Chinese Society of Agricultural Engineering (Transactions of the CSAE). 2018, 34(6):1-14.

Berroug, F., Lakhal, E.K., El-Omari, M. et al., 2011. Thermal performance of a greenhouse with a 
phase change material north wall. Energy Build. 43, 3027-3035.

Bazgaoua, A., Fatnassib, H., Bouhroudc, R. et al., 2018. An experimental study on the effect of a rock-bed heating system on the microclimate and the crop development under canarian greenhouse. Solar Energy. 176, 42-50.

Benoit, L., Spreafico, D., Gauthier, G., Flamant, G., 2016. Review of heat transfer fluids in tube-receivers used in concentrating solar thermal systems: properties and heat transfer coefficients. Renew. Sustain. Energy Rev. 55, 298-315.

Cao Z., Zhang Z., Chen J., 2016. Simulation on heat collection performance of a parabolic trough coleector. Power Equipment. 30(5), 308-313.

Chao, C., Haoshu, L., Zhiqiang, Z. et al., 2018. Thermal performance of an active-passive ventilation wall with phase change material in solar greenhouses. Applied Energy. 216, 602-612.

Chao, C., Nan, Y., Fengguang, Y. et al., 2019. Theoretical and experimental study on selection of physical dimensions of passive solar greenhouses for enhanced energy performance. Solar Energy. $191,46-56$.

Chen, C., Zhang, M., Zheng, H., et al. 2017. Thermal performance experiment for multiple clamber trough solar air collector with dual collector tubes for solar greenhouse. Transactions of the Chinese Society of Agricultural Engineering. 33(15), 245-252.

Chamsa-ard, Wisut, Sukchai, Sukruedee, Sonsaree, Sorawit., 2014. Thermal performance testing of heating pipe evacuated tube with compound parabolic concentrating solar collector by ISO 9806-1. Energy Proc. 56, 237-46.

El-Maghlany, W.M., Teamah, M.A., Tanaka, H., 2015. Optimum design and orientation of the greenhouses for maximum capture of solar energy in North Tropical Region. Energy Conversion and Management. 105, 1096-1104.

Gnieinski, V., 1976. New equations for heat mass transfer in turbulent pipe and channel flows. Int Chem Eng. 16, 359-368.

Hsieh, C. K., 1981. Thermal analysis of CPC collectors. Solar Energy. 27(1), 19-29.

Hung, T., Huang, T., Lee, D. et al., 2017. Numerical analysis and experimental validation of heat transfer characteristic for flat-plate solar air collector. Applied Thermal Energy. 111, 1025-1038.

Haoshu Ling, Liang Wang, Chao Chen et al., 2019. Effect of thermophysical properties correlation of 
phase change material on numerical modelling of agricultural building. Applied Thermal Engineering. 157, 113579.

Islam, M. T., Huda, N., Abdullah, A. B. et al., 2018. A comprehensive review of state-of-the-art concentrating solar power (CSP) technologies: current status and research trends. Renewable and Sustainable Energy Reviews. 91, 987-1018.

Kooli, S., Bouadila, S. et al., 2015. The effect of the nocturnal shutter on insulated greenhouse using a solar air heater with latent storage energy. Solar Energy. 115, 217-228.

Lazaar, M., Bouadila, S. et al., 2015. Comparative study of conventional and solar heating systems under tunnel Tunisian greenhouses: Thermal performance and economic analysis. Solar Energy. $120,620-635$.

Li, Cho-Yen, Sari, Fitri Nur Indah, Ting, Jyh-Ming, 2019. Reactive magnetron sputter deposited TiNxOy multilayered solar selective coatings. Solar Energy. 181, 178-186.

Ling, H., Chen, C., Guan Y. et al., 2014. Active heat storage characteristics of active-passive triple wall with phase change material. Solar Energy. 110, 76-285.

Ling, H., Chen C., Qin H. et al., 2016. Indicators evaluating thermal inertia performance of envelops with phase change material. Energy and Buildings. 122,175-184.

Ling, H., 2017. Study on novel active-passive wall with phase change material in solar greenhouse and its thermal performance. $\mathrm{PhD}$ thesis, Beijing University of Technology, Beijing, China.

Ma, X., Zheng, H., Liu, H., 2019. A review on solar concentrators with multi-surface and multi-element combinations. Journal of Daylighting. 6, 80-96.

Mohammadi, M., Hematiyan, M.R., Marin, L., 2010. Boundary element analysis of nonlinear transient heat conduction problems involving non-homogenous and nonlinear heat sources using time-dependent fundamental solutions. Eng. Anal. Boundary Elem. 34 (7), 655-665.

Naijun, Z., Yaxiong, Y., Jinping, Y. et al., 2017. A study on thermal calculation method for a plastic greenhouse with solar energy storage and heating. Solar Energy, 142, 39-48.

Ntinas, G.K., Fragos, V.P., Nikita-Martzopoulou, Ch., 2014. Thermal analysis of a hybrid solar energy saving system inside a greenhouse. Energy Convers. Manage. 81, 428-439.

Ramakrishnan, S., Wang, X.M., Sanjayan, J. et al., 2017. Thermal performance of buildings integrated with phase change materials to reduce heat stress risks during extreme heatwave events. Applied 
Energy. 194, 410-421.

Santos-Gonalez, I., Garcia-Valladares, O. et al., 2017. Numerical modeling and experimental analysis of the thermal performance of a compound parabolic concentrator. Applied Thermal Engineering. 11, $41152-41160$.

Sethi, V.P., Sumathy, K., Lee, Chiwon, Pal, D.S., 2013. Thermal modeling aspects of solar greenhouse microclimate control. Solar Energy. 96, 56-82.

Sethi, V., Sharma, S., 2008. Survey and evaluation of heating technologies for worldwide agricultural greenhouse applications. Solar Energy. 82(9), 832-859.

H. Singh, P.C. Eames, 2012. Correlation for natural convective heat exchange in CPC solar collector cavities determined from experimental measurements. Solar Energy. 86, 2443-2457.

Tao, T., Zheng, H., He, K. et al., 2011. A new trough solar concentrator and its performance analysis. Solar Energy. 85, 198-207.

Tolga Ural, 2019. Experimental performance assessment of a new flat-plate solar air collector having textile fabric as absorber using energy and exergy analyses. Energy. 188, 116116.

Tong K., Yang L., Song J. et al., 2019. Review on Advanced Technology of Concentrated Solar Power Concentrators. Power Generation Technology. 40(5):413-425.

Wei, B., Guo, S.R., Wang, J., et al., 2016. Thermal performance of single span greenhouses with removable back walls. Biosyst Eng. 141, 48-57.

Wenye Lin, Haoshan Ren, Zhenjun Ma, 2020. Mathematical modelling and experimental investigation of solar air collectors with corrugated absorbers. Renewable Energy. 145, 164-179.

Willmott, C.J., 1981. On the Validation of Models. Physical Geography. 2, 184-194.

Yataganbaba, A., Ozkahraman, B., Kurtbas I., 2017. Worldwide trends on encapsulation of phase change materials: a bibliometric analysis (1990-2015). Applied Energy. 185, 720-731.

Yuexia, Lv, Pengfei, Si, Xiangyang, Rong, et al., 2018. Determination of optimum tilt angle and orientation for solar collectors based on effective solar heat collection. Applied Energy. 219, $11-19$.

Yildirim Nurdan, Bilir Levent, 2017. Evaluation of a hybrid system for a nearly zeroenergy greenhouse. Energy Convers. Manage. 148, 1278-1290.

Zhang Ximin, Ren Zepei, Mei Feiming et al., 2007. Heat Transfer. China Architecture 
\& Building Press, Beijing, China, 341p, ISBN 978-7-112-09183-6.

Zheng, H., Tao T., Ma, M. et al., 2012. Experimental test of a novel multi-surface trough solar concentrator for air heating. Energy Conversion and Management. 63, 123-129.

Zheng, W., Yang, L., Zhang, H. et al., 2016. Numerical and experimental investigation on a new type of compound parabolic concentrator solar collector. Energy Conversion and Management. 129, $11-22$.

Zhang, X., Wang, H.L., Zou, Z.R. et al., 2016. CFD and weighted entropy based simulation and optimisation of Chinese Solar Greenhouse temperature distribution. Biosyst Eng. 142, 12-26.

Zou, B., Dong, J., Yao, Y., Jiang, Y., 2016. An experimental investigation on a small-sized parabolic trough solar collector for water heating in cold areas. Applied Energy. 163, 396-407. 